\title{
Peptidoglycan-Modifying Enzyme Pgp1 Is Required for Helical Cell Shape and Pathogenicity Traits in Campylobacter jejuni
}

\author{
Emilisa Frirdich ${ }^{1}$, Jacob Biboy ${ }^{29}$, Calvin Adams ${ }^{39}$, Jooeun Lee ${ }^{4}$, Jeremy Ellermeier ${ }^{5}$, Lindsay \\ Davis Gielda ${ }^{5}$, Victor J. DiRita ${ }^{5}$, Stephen E. Girardin ${ }^{4}$, Waldemar Vollmer ${ }^{2}$, Erin C. Gaynor ${ }^{1 *}$
}

1 Department of Microbiology and Immunology, University of British Columbia, Vancouver, British Columbia, Canada, 2 The Centre for Bacterial Cell Biology, Institute for Cell and Molecular Biosciences, Newcastle University, Newcastle upon Tyne, United Kingdom, 3 Wine Research Centre, Faculty of Land and Food Systems, University of British Columbia, Vancouver, British Columbia, Canada, 4 Department of Laboratory Medicine and Pathobiology, University of Toronto, Toronto, Ontario, Canada, 5 Department of Microbiology and Immunology \& Unit for Laboratory Animal Medicine, University of Michigan Medical School, Ann Arbor, Michigan, United States of America

\begin{abstract}
The impact of bacterial morphology on virulence and transmission attributes of pathogens is poorly understood. The prevalent enteric pathogen Campylobacter jejuni displays a helical shape postulated as important for colonization and host interactions. However, this had not previously been demonstrated experimentally. C. jejuni is thus a good organism for exploring the role of factors modulating helical morphology on pathogenesis. We identified an uncharacterized gene, designated pgp1 (peptidoglycan peptidase 1), in a calcofluor white-based screen to explore cell envelope properties important for $C$. jejuni virulence and stress survival. Bioinformatics showed that Pgp1 is conserved primarily in curved and helical bacteria. Deletion of pgp1 resulted in a striking, rod-shaped morphology, making pgp1 the first $C$. jejuni gene shown to be involved in maintenance of $C$. jejuni cell shape. Pgp1 contributes to key pathogenic and cell envelope phenotypes. In comparison to wild type, the rod-shaped pgp 1 mutant was deficient in chick colonization by over three orders of magnitude and elicited enhanced secretion of the chemokine IL-8 in epithelial cell infections. Both the pgp1 mutant and a pgp1 overexpressing strain - which similarly produced straight or kinked cells - exhibited biofilm and motility defects. Detailed peptidoglycan analyses via HPLC and mass spectrometry, as well as Pgp1 enzyme assays, confirmed Pgp1 as a novel peptidoglycan DL-carboxypeptidase cleaving monomeric tripeptides to dipeptides. Peptidoglycan from the pgp 1 mutant activated the host cell receptor Nod1 to a greater extent than did that of wild type. This work provides the first link between a C. jejuni gene and morphology, peptidoglycan biosynthesis, and key host- and transmission-related characteristics.
\end{abstract}

Citation: Frirdich E, Biboy J, Adams C, Lee J, Ellermeier J, et al. (2012) Peptidoglycan-Modifying Enzyme Pgp1 Is Required for Helical Cell Shape and Pathogenicity Traits in Campylobacter jejuni. PLoS Pathog 8(3): e1002602. doi:10.1371/journal.ppat.1002602

Editor: Steven R. Blanke, University of Illinois, United States of America

Received August 27, 2011; Accepted February 8, 2012; Published March 22, 2012

Copyright: (c) 2012 Frirdich et al. This is an open-access article distributed under the terms of the Creative Commons Attribution License, which permits unrestricted use, distribution, and reproduction in any medium, provided the original author and source are credited.

Funding: This work was funded by Canadian Institutes of Health Research CIHR MOP-68981 and the Burroughs Wellcome Fund (ECG), National Institute of Allergy and Infectious Disease AI069383 (VJD), and bridging funds from the Wellcome Trust and Newcastle University (WV). URLs: http://www.cihr-irsc.gc.ca/e/193. html; http://www.bwfund.org/; http://www.niaid.nih.gov/; http://www.wellcome.ac.uk/; http://www.ncl.ac.uk/) The funders had no role in study design, data collection and analysis, decision to publish, or preparation of the manuscript.

Competing Interests: The authors have declared that no competing interests exist.

*E-mail: egaynor@mail.ubc.ca

9 These authors contributed equally to this work.

\section{Introduction}

Campylobacter jejuni is a helical, highly motile, Gram-negative $\varepsilon$ Proteobacterium and a prevalent zoonotic organism existing asymptomatically in the intestinal tract of birds and other animal species [1-3]. However, ingestion of as few as 500 bacteria can result in human disease [4]. C. jejuni is the leading cause of foodborne gastroenteritis in the developed world, causing an acute self-limiting infection of varying severity that can give rise to severe complications such as inflammatory bowel disease, reactive arthritis, and Guillain-Barré syndrome (GBS) [5].

C. jejuni lacks many of the frequently identified virulence factors encoded by other enteric pathogens such as pili, enterotoxins, and specialized secretion mechanisms [6,7]. Genes affecting fundamental aspects of C. jejuni biology in hosts other than humans, such as stress survival, transmission, and asymptomatic colonization, also affect virulence in disease models. We found that $C$. jejuni strain 81-176 binds calcofluor white (CFW), a compound that reacts with $\beta 1-3$ and $\beta 1-4$ carbohydrate linkages and fluoresces under long wave UV light $[8,9]$. The carbohydrate responsible for CFW reactivity in $C$. jejuni has not yet been identified, although it was previously shown not to be one of the well-characterized surface polysaccharides expressed by $C$. jejuni: the capsular polysaccharide, lipooligosaccharide (LOS), N-linked glycoproteins, or O-linked flagellar glycoproteins [10]. C. jejuni mutants with altered CFW reactivity can be readily identified in screens. All $C$. jejuni CFW hyper- or hyporeactive mutants characterized to date exhibit changes in pathogenesis, virulence, fundamental, and/or stress survival phenotypes ([10,11]; E. Frirdich and E. C. Gaynor, unpublished). For instance, CFW hyper-reactive mutants overproduce biofilms, while hypo-reactive mutants are biofilmdefective. Other attributes associated with altered CFW reactivity 


\section{Author Summary}

Bacterial cell shape is dictated by the composition of the cell envelope component peptidoglycan. Some important pathogens have a characteristic helical corkscrew morphology that may help them burrow into mucus overlaying cells to initiate colonization and pathogenicity. One example is Campylobacter jejuni, the leading cause of bacterial-induced diarrheal disease in the developed world. Direct evidence supporting the hypothesis that $C$. jejuni shape is related to its pathogenicity traits has not previously been provided. We identified a gene encoding a peptidase modifying peptidoglycan that is essential for maintaining the $C$. jejuni corkscrew shape. We can now connect a $C$. jejuni gene with morphology and peptidoglycan biosynthesis. Loss of this gene was also found to affect pathogenic attributes such as chicken colonization, biofilms, motility, and activation of host inflammatory mediators. In addition, this is the first study to thoroughly characterize $C$. jejuni peptidoglycan structure and to identify a gene involved in peptidoglycan maintenance. Our findings highlight an emerging theme in bacterial pathogenesis research: the connection between bacterial cell biology and pathogenesis. Finally, our characterization of C. jejuni cell shape and peptidoglycan provides a starting point for further work in this area in C. jejuni and other bacteria with curved and helical morphologies.

have included defects in colonization, host cell interactions, cell envelope components, and stress survival. A CFW hypofluorescent mutant with a lesion in a novel peptidoglycan peptidase gene (pgp1) serves as the basis of this study.

The helical shape of C. jejuni has long been postulated to be critical for pathogenic attributes such as the ability to burrow through the mucosal layer during infection of zoonotic and human hosts. However, genetic components involved in modulating $C$. jejuni morphology had not previously been identified. Morphology is maintained in most bacteria by the peptidoglycan (PG) layer [12]. PG is composed of glycan chains consisting of $\beta 1-4$ linked $\mathrm{N}$ acetylglucosamine (GlcNAc) and $\mathrm{N}$-acetylmuramic acid (MurNAc) residues that are cross-linked by short peptides. PG synthesis is a highly regulated process $[13,14]$ taking place at the bacterial inner membrane, where lipid II precursors are polymerized by glycosyltransferase and DD-transpeptidase reactions. In addition to the synthetic enzymes, PG hydrolases are required to cleave bonds in PG or PG fragments for insertion of nascent PG into the mature layer, regulation of cell wall growth, cell separation, PG turnover and recycling, cell lysis, and the release of PG fragments in host-pathogen interactions [15]. Almost every glycosidic and amide bond in PG can be cleaved by one or more specific PG hydrolases, and this redundancy makes it difficult to assign a specific function to a hydrolase $[15,16]$. It has been speculated that murein synthases and hydrolases are part of a multienzyme complex for PG assembly [16], and several interactions between PG enzymes have been reported [14].

Campylobacter PG contains meso-diaminopimelic acid (meso-Dap) in its peptide side chains and is modified by $\mathrm{O}$-acetylation $[17,18]$, but the detailed muropeptide composition had not previously been elucidated. Bioinformatic analyses identified 3 putative PG synthases in C. jejuni: the penicillin-binding proteins (PBPs) PBP1A (cjj81176_0536), PBP (cjj81176_0550), and PBP2 (cjj81 176_0680), but there are no predicted homologs of low-molecular weight PBPs such as DD-endo- or carboxypeptidases. C. jejuni does have homologs of the Csdl and GcmA endopeptidases and of the Cisd3/HdpA endo/carboxypeptidase discovered recently in Heli- cobacter pylori $[19,20]$. Deletion of each of these genes in $H$. pylori resulted in curved-rod morphologies with reduced levels of PG cross-linking [19], but preliminary evidence indicates that these enzymes may have a different function in C.jejuni (E. Frirdich and E. C. Gaynor, unpublished).

Here, we report the first $C$. jejuni gene, pgp1, to be identified with a role in helical morphology. Structural PG analyses of $C$. jejuni wild-type 81-176 and $\Delta p g p 1$ mutant strains showed striking alterations in the mutant, with enzyme assays confirming Pgpl as a novel DL-carboxypeptidase. Furthermore, using the $\Delta p g p 1$ mutant with a straight morphology, the importance of $C$. jejuni helical shape and PG in pathogenesis attributes was examined; we identified roles in motility, biofilm formation, chick colonization, and stimulation of host cell proinflammatory mediators Nodl and IL-8.

\section{Results}

CFW screen for hypofluorescent mutants identifies the $C$. jejuni 81-176 gene pgp1

As noted, screening for C. jejuni hypofluorescent mutants was previously shown to identify genes involved in pathogenesis-related phenotypes [10]. However, as the $\operatorname{Tn} 7$ transposon (Tn) used previously for mutant library construction was reproducibly found to have inserted in intergenic regions (M. K. McLennan and E. C. Gaynor, unpublished), a new random Tn library was generated as part of this study, using the highly efficient mariner system of in vitro Tn mutagenesis developed for C. jejuni [21]. The mariner library was plated onto CFW-containing plates and, from approximately 10, 000 colonies screened, 400 hypofluorescent mutants were isolated. Of the Tn insertions mapped, 8 were in distinct regions of the gene cjj81176_1344 (Figure 1; the CFW hypofluorescent phenotype is described below). The 1344 gene was named pgp1 (peptidoglycan peptidase 1) to describe its function and identification as the first C. jejuni PG peptidase to be characterized.

The $p g p 1$ gene product is highly conserved in mainly helical and vibrioid bacteria, primarily within the $\varepsilon$ - and $\delta$-Proteobacteria but also in a few extremophiles outside the $\varepsilon$-Proteobacteria (Table S1). The H. pylori homolog is described by Sycuro et al. [22]. Pgpl was annotated as a putative periplasmic protein. However, bioinformatics using conserved domain searches and the threading program PHYRE identified an N-terminal signal peptide, a zinc binding site, and metallocarboxypeptidase catalytic residues and folds. Pgpl contains a conserved domain at its N-terminus similar to that of the M14 family of metallocarboxypeptidases.

\section{Non-polar insertional deletion of pgp1 and complementation of a pgp 1 mutant}

To explore functional consequences of loss of Pgpl function in C. jejuni, a non-polar pgp1 targeted deletion strain was constructed (designated $\Delta p g p 1$ above the gene cluster in Figure 1). To verify lack of polar effects on the downstream gene, an insertional mutation was also created in 1343 . The $\Delta 1343$ mutant exhibited wild-type phenotypes for shape, motility, biofilm formation and CFW reactivity (data not shown; these phenotypes for $\Delta p g p 1$ are described below). The level of $1343 \mathrm{mRNA}$ was also determined to be identical in $\Delta p g p 1$ and in the wild-type strains by semiquantitative RT-PGR (data not shown)

The $p g p 1$ gene is located in the middle of a putative operon, and the location of the $p g p 1$ promoter is unclear from sequence analysis (Figure 1). Therefore, complementation was first attempted by expressing the $p g p 1$ gene from the cat promoter of the vector pRRG $\left(\mathrm{Cm}^{\mathrm{R}}\right)$ [23] integrated into an rRNA spacer region of 


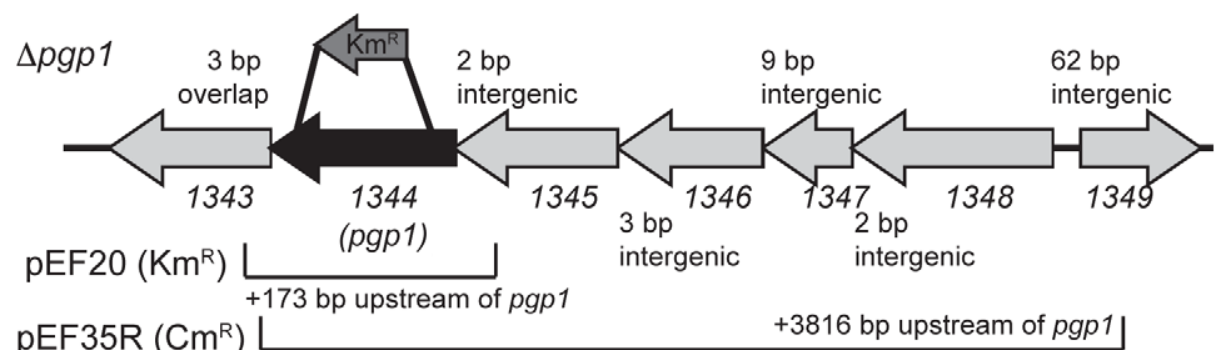

$\Delta p g p 1 c(\Delta p g p 1$ integrated with pEF35R)

Figure 1. C. jejuni 81-176 pgp1 gene locus. $\Delta p g p 1$ was constructed by deleting 880 bp of pgp 1 and inserting the non-polar aphA-3 $\mathrm{Km}^{\mathrm{R}}$ cassette; the approximate location of this insertion is shown above the gene cluster and is denoted by the $\Delta p g p 1$ strain designation. The regions cloned into the integrative vectors pRRC (pEF35R; $\mathrm{Cm}^{\mathrm{R}}$ ) or pRRK $\left(\mathrm{pEF} 20 ; \mathrm{Km}^{\mathrm{R}}\right)$ used for complementation and overexpression, respectively, are shown below the gene cluster. An R after the plasmid name indicates that the region is cloned in the opposite direction as the antibiotic resistance cassette promoter. doi:10.1371/journal.ppat.1002602.g001

$\Delta p g p 1$. This construct contained a similar region of $p g p 1$ as shown for pEF20 in Figure 1 (pEF20 will be described further below) and did not complement $\Delta p g p 1$ (data not shown). However, integration of this same construct into the C.jejuni wild type strain also resulted in morphological and phenotypic alterations (described below), suggesting that $p g p 1$ copy number was likely important for complementation, and that the level of pgp1 expression from the cat promoter was higher than optimal. To generate a complementing strain expressing $p g p 1$ from its native promoter, increasing amounts of the region upstream of $p g p 1$ were cloned with $p g p 1$ into pRRC. These regions were cloned in the opposite direction as cat (to avoid overexpression from the cat promoter) and integrated into an rRNA spacer region of $\Delta p g p 1$. These constructs yielded varying degrees of complementation, with the pEF35R (Figure 1) construct complementing nearly all $\Delta p g p 1$ phenotypes to wild-type levels. The complemented strain was verified by PCR and designated $\Delta p g p l \mathrm{c}$.

\section{The pgp 1 gene is required for helical morphology, and $\Delta p g p 1$ is deficient in CFW reactivity, motility, and biofilm formation}

Since the $p g p 1$ gene product is highly conserved in helical and vibrioid bacteria, the morphology of the $\Delta p g p 1$ mutant was examined. The $\Delta p g p 1$ mutant displayed a striking change compared to wild type and had lost the characteristic helical shape (Figure 2A), adopting a straight morphology (Figure 2B). Complementation restored the helical shape in approximately 95\% of the cells (Figure 2C).

Consistent with the phenotype of the mariner insertion mutants, the $\Delta p g p 1$ mutant was hyporeactive to $\mathrm{CFW}$, with wild-type reactivity restored by complementation (Figure 2D). The $\Delta p g p 1$ mutant displayed no obvious flagellar structural defects (Figure 2B), but did exhibit a slight motility defect after incubation for $20 \mathrm{~h}$ on $0.4 \%$ agar plates, producing halos that were, on average, about $82.5 \%$ of wild type (Figure 2E). Motility was restored to wild-type levels in the complemented strain. Biofilm levels, as assessed by a crystal violet assay, were approximately 1.2-, 1.5- and 1.6-fold lower in the $\Delta p g p 1$ mutant compared to wild type at days 1,2 , and 3 , respectively. Biofilm production was partially restored in $\Delta p g p 1 \mathrm{c}$ (Figure 2F). No differences between wild type and $\Delta p g p 1$ were observed for growth, stress survival, capsule and LOS migration on acrylamide gels, membrane protein composition, and sensitivity to antimicrobial compounds (Table S2).

\section{Pgp1 overexpression also affects helical morphology}

To assess the effects of $p g p 1$ overexpression, $p g p 1$ was expressed from either the cat or aphA-3 promoter in pRRC (data not shown) or pRRK (pEF20 in Figure 1), respectively, and integrated at an rRNA spacer region of wild-type C. jejuni. Both pRRC and pRRK derivatives had the same effects on wild type, so only the results for pEF20 are shown. The pgp1 overexpressing strain displayed an altered cell shape in approximately $50 \%$ of the population, producing kinked and straight cells among the helical cells (Figure 3A). This strain also exhibited reduced motility and a defect in biofilm formation (Figure 3B \& C). Reverse transcriptasequantitative PCR (RT-qPCR) confirmed that the levels of $p g p 1$ mRNA were 5.1 -fold higher in the overexpressing strain than in wild type. In addition, there was a 1.2-fold increase in $p g p 1 \mathrm{mRNA}$ levels in the complementing strain $\Delta p g p 1 \mathrm{c}$ in comparison to wild type, which may explain the partial complementation of some phenotypes. Expression of pgp1 in E. coli had no effect on cell shape (data not shown).

\section{Peptidoglycan analysis}

Muropeptide profile of wild-type $C$. jejuni 81-176 reveals numerous stem peptide species. Given the shape phenotype of the pgp1 mutant strains and the putative peptidase domain of Pgpl, we hypothesized that Pgpl cleaves the PG stem peptide. Since C. jejuni PG had not been fully characterized, we first analyzed the muropeptide composition of wild type. The HPLC analysis is shown in Figure 4A, and the structure of individual muropeptides (Figure 4E) was confirmed by co-elution with known muropeptides from E. coli [24] and by LTQ-FT-MS/MS (Table 1; raw data in Tables S3 and S4) [25].

The most abundant muropeptides were the monomers with di-, tri- and tetrapeptides, as well as dimeric 4-3 cross-linked TetraTetra and TetraTri species. Only one very minor peak with a pentapeptide side chain was detected in C. jejuni, a TetraPenta dimer with a Gly residue at position 5, as opposed to the more common D-Ala. Muropeptides with 3-3 crosslinks or Lys-Arg residues indicating bound lipoprotein were not detected and thus are either not present or present in very small amounts. The degree of cross-linking at $29.5 \%$ is consistent with the value of $30 \%$ published previously [17]. The average glycan chain length determined by the fraction of 1,6-anhydromuramic acid containing muropeptides from chain ends was 14.7 dissacharide units. The PG glycan backbone of two different strains of $C$. jejuni was reported to be modified with O-acetyl groups at levels of $55.7 \%$ and $62 \%$ relative to MurNAc content [18]. The fact that we observed lower levels of $\mathrm{O}$-acetylation in our analyses $(5.7 \%)$ is likely due to the loss of most of the labile O-acetyl groups in the standard alkaline muropeptide reduction procedure applied in this study. 


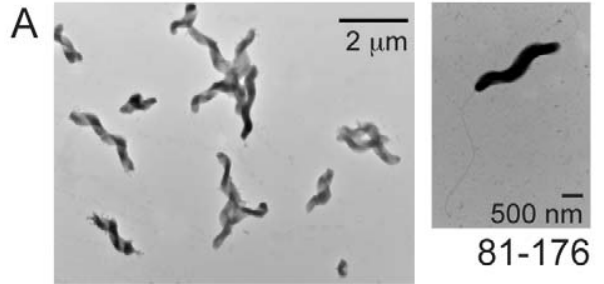

B
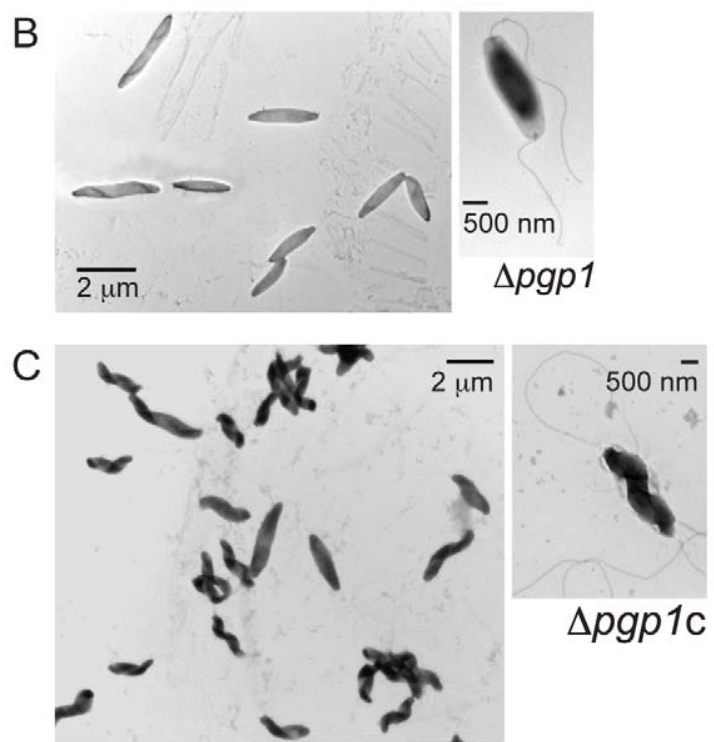
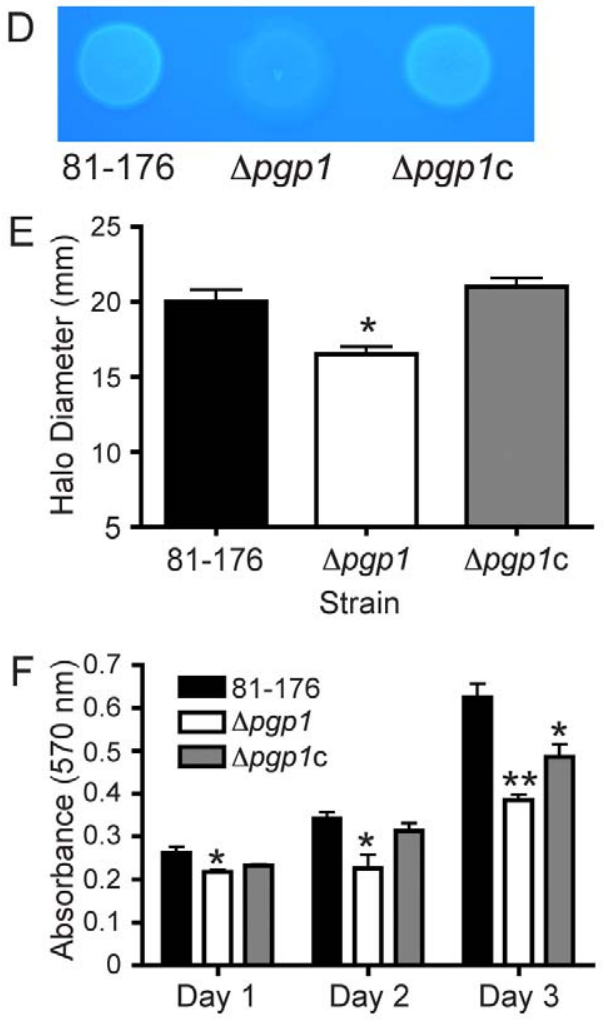

Figure 2. A pgp1 mutant has a straight morphology and defects in CFW reactivity, motility, and biofilms. Negatively stained TEM images of $\mathbf{A}$, the helical C. jejuni 81-176 strain; B, the straight $\Delta p g p 1$ strain with intact flagella; and $\mathbf{C}$, the complemented strain $\Delta p g p 1 \mathrm{c}$ with restored helical morphology in $95 \%$ of the population. D, $\Delta p g p 1$ is hypofluorescent after $48 \mathrm{~h}$ of growth on plates containing $0.002 \%$ CFW which is restored by complementation. E, $\Delta p g p$ 1exhibits a slight motility defect, as assayed by measuring halo diameters in soft agar plates. Standard error of the mean was calculated from 12 measurements. F, $\Delta p g p 1$ is defective for biofilm formation, partially complemented in $\Delta p g p 1 c$. Biofilm formation was assessed by crystal violet staining of standing cultures in borosilicate tubes and quantification of dissolved crystal violet at $570 \mathrm{~nm}$. Standard errors of the mean were calculated from triplicate cultures and are representative of three independent experiments. The asterisk (*) indicates a statistically significant difference using the unpaired Student's t-test, with * or ** indicating $p<0.05$ or $p<0.01$, respectively. Numerous other phenotypes showed no difference from wild type (Table S2).

doi:10.1371/journal.ppat.1002602.g002

Loss of pgp1 and Pgp1 overexpression result in altered PG muropeptide profiles. PG from the $\Delta p g p 1$ mutant, complement $(\Delta p g p 1 \mathrm{c})$, and $p g p 1$ overexpression $(81-176+p g p 1)$ strains was isolated, and the muropeptide profiles were analyzed by HPLC as above (Figure 4A-D, Tables 1 and S4). The $\Delta p g p 1$ mutant exhibited a number of changes from wild type, most significantly a striking increase in tripeptides and reduced dipeptides and tetrapeptides. The overexpression strain $(81-176+p g p 1)$ exhibited the opposite profile from $\Delta p g p 1$, with a decrease in total tripeptides, an increase in total dipeptides, and to a lesser extent, an increase in tetrapeptides and Gly-containing pentapeptides. Complementation restored many of the changes in $\Delta p g p 1$ to near-wild-type levels; however, $p g p 1$ may be modestly overexpressed in $\Delta p g p 1 \mathrm{c}$ based on some similarities to the $81-176+p g p 1$ profile. The overall degree of crosslinking did not vary significantly between the different strains. Together with sequence analysis (see above), the PG data suggests Pgp1 functions as a DL-carboxypeptidase, hydrolyzing the D-Glumeso-Dap bond in tripeptides to form dipeptides. Loss of most Oacetyl groups in the PG preparation techniques used in this study precluded exact quantification of this $\mathrm{PG}$ glycan backbone modification in the $\Delta p g p 1$ mutant. As PG O-acetylation confers resistance to lysozyme [26,27], it would be expected that if Pgpl affects $\mathrm{O}$-acetylation, the $\Delta p g p 1$ mutant would display a change in lysozyme sensitivity. In the presence of the metal chelator EDTA to permeabilize the outer membrane, no difference in $\mathrm{MIC}$ for lysozyme was observed between wild type and $\Delta p g p 1$ strains (Table S2). Biochemical analyses (described below) confirming Pgpl as a DL-carboxypeptidase cleaving the $\mathrm{PG}$ stem peptide further suggested no functional involvement of Pgpl in O-acetylation, thus additional experiments to assess this were not pursued.

Pgp1 is a metal-dependent DL-carboxypeptidase cleaving monomeric disaccharide tripeptides to dipeptides. Pgp 1 protein was expressed and purified from E. coli (Figure 5A) and incubated with purified $\Delta p g p 1 \mathrm{PG}$ to assess the biochemical function of the protein. The resultant PG was analyzed as above, and the muropeptide profiles were compared to that of $\Delta p g p 1$ (Figure 5B-D, Tables 1 and S4). In the presence of $\mathrm{ZnCl}_{2}$, the addition of Pgpl resulted in a striking increase in monomeric dipeptides with a concomitant decrease in monomeric tripeptides, characteristic of a metal-dependent DL-carboxypeptidase (Figure 5C; Table 1). This activity was eliminated in the absence of $\mathrm{ZnCl}_{2}$ with added EDTA, establishing the dependence of Pgpl on divalent ions (Figure 5D). This confirmed Pgpl as a metal-dependent DL-carboxypeptidase cleaving monomeric disaccharide tripeptides to dipeptides (Figure 5E).

\section{The effect of pgp1 on host-related phenotypes}

$\Delta p g p 1$ is defective for in vivo chick colonization. A $C$. jejuni chick colonization model was used to determine the role of 
A

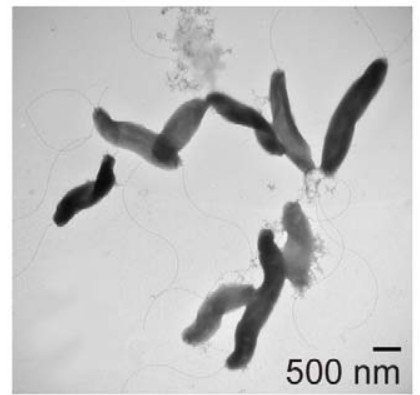

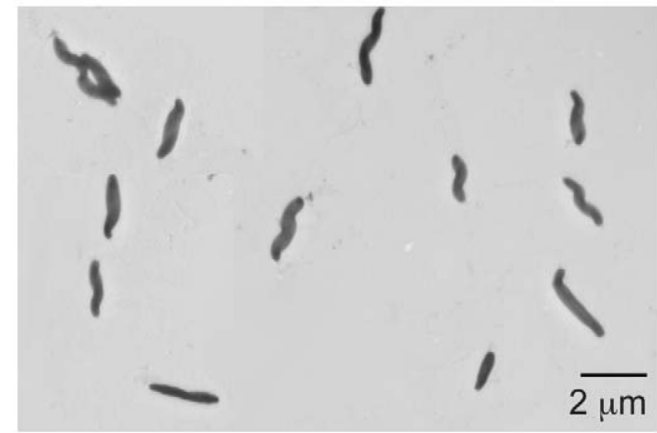

C

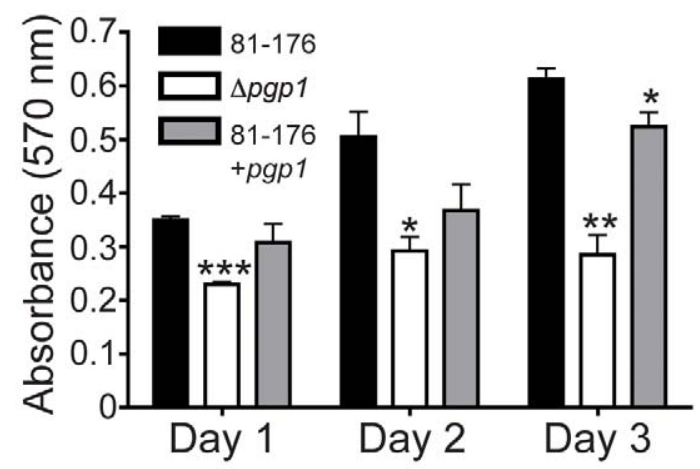

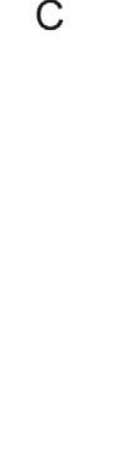

B

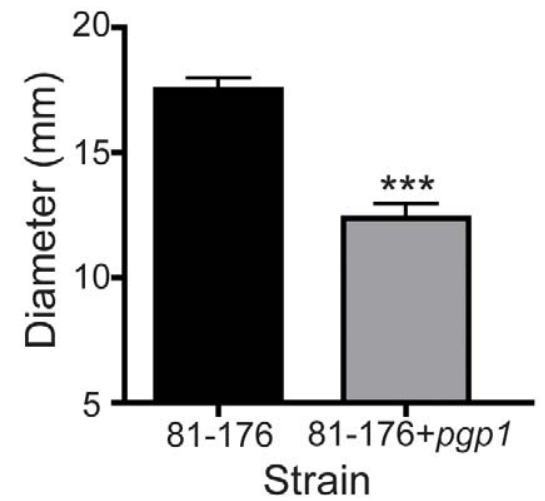

Figure 3. Overexpression of pgp1 in the wild-type strain has cell straightening effects and causes reduced motility and a biofilm formation defect. The $p g p 1$ gene was overexpressed by integration of pgp1 expressed from the aphA-3 promoter from pEF20 into C. jejuni 81-176. A, negatively stained TEM images of C. jejuni 81-176 overexpressing pgp1. B, motility assayed by measuring halo diameter of growth in soft agar plates. Error bars were calculated from 12 measurements. C, biofilm formation was assessed by crystal violet staining of standing cultures in borosilicate tubes and quantification of dissolved crystal violet at $570 \mathrm{~nm}$. Standard errors of the mean were calculated from triplicate readings and are representative of three independent experiments. The asterisk $(*)$ indicates a statistically significant difference using the unpaired Student's t-test, with $* * *$, or $* * *$ indicating $p<0.05, p<0.01$ or $p<0.001$, respectively.

doi:10.1371/journal.ppat.1002602.g003

pgp1 in vivo. One-day old chicks were infected orally with a dose of $10^{4}$ C. jejuni wild-type 81-76, $\Delta p g p 1$, or $\Delta p g p 1 \mathrm{c}$, and cecal contents were assessed for $C$. jejuni after 6 days. The $\Delta p g p 1$ mutant exhibited a statistically significant $(p$ 0.0009) 2.9-log decrease in average levels of colonization compared to wild type (Figure 6A). Complementation restored colonization levels to within 0.5-log of wild type (Figure 6A). As a control to explore whether the slight motility defect of $\Delta p g p 1$ may be responsible for the reduction in chick colonization, we also infected chicks with a $\Delta$ car $B$ mutant [10]. $c a r B$ encodes carbamoylphosphate synthase and is directly downstream of an intergenic Tn7 insertion in a CFW hypofluorescent mutant $(\operatorname{dim} 13)$ isolated in a previous screen [10]. A $\Delta$ carB mutant had wild-type helical morphology, but displayed a slight motility defect of approximately $86.0 \%$ that of wild-type (Figure S1) and a hypofluorescent phenotype on CFW similar to $\Delta p g p 1[10]$. However, unlike $\Delta p g p 1$, the $\Delta$ carB mutant showed no statistically significant change in chick colonization (Figure S1).

In vitro invasion and intracellular survival in epithelial and macrophage cell lines are not dramatically affected in Apgp1. The human epithelial cell lines T84, Caco-2 and INT407, and the murine RAW 264.7 and human Thp-1 macrophage cell lines were used in gentamicin protection assays to examine the role of $p g p 1$ in C. jejuni invasion and intracellular (IC) survival in vitro. No defects in invasion were observed for any cell line ( $2 \mathrm{~h}$ post gentamicin treatment). In epithelial cells, $\Delta p g p 1$ exhibited a $0.5 \log$ increase in IC survival compared to wild type
$7 \mathrm{~h}$ post gentamicin treatment (shown for Caco-2 cells in Figure $\mathrm{S} 2$ ). This was also seen at $5 \mathrm{~h}$ and $9 \mathrm{~h}$ (data not shown), but not at $21 \mathrm{~h}$ post gentamicin treatment. No differences in IC survival were observed in either macrophage cell line tested (data not shown).

Because of the modest motility defect of $\Delta p g p 1$ in soft agar, we also wished to assess whether attachment and invasion might be altered in a tissue culture medium of higher viscosity. MEM supplemented with carboxymethylcellulose (CMC) was previously used to demonstrate increased host cell attachment and invasion for some strains of $C$. jejuni in a higher viscosity medium [28]. INT407 cells were infected with $C$. jejuni 81-176 and $\Delta p g p 1$ in MEM containing GMC. No significant difference in invasion was seen after $1 \mathrm{~h}$ or $3 \mathrm{~h}$ with the addition of $0.6 \%, 1 \%$ or $2 \% \mathrm{CMC}$ (Figure S2). Furthermore, GMC addition decreased the total levels of invaded bacteria for both the wild type and mutant strains.

PG changes in $C$. jejuni $\Delta p g p 1$ result in an altered epithelial cell Nod1 response. PG is recognized by Nod-like receptors of the innate immune system. To test whether the PG changes resulting from a $p g p 1$ mutation altered Nod receptor stimulation, we measured expression of a NF- $\kappa \mathrm{B} \lg k$ luciferase reporter transfected in human embryonic kidney HEK293T cells along with either the human (h)Nodl, mouse (m)Nodl, or human (h)Nod2 receptor (Figure 6B-D). We found that PG from the $\Delta p g p 1$ mutant produced a statistically significant increase in mNodl activation compared to wild type. In contrast, $\Delta p g p 1$ mutant PG did not produce a statistically significant change in stimulation of hNodl, despite a modest increase from wild type. $C$. 

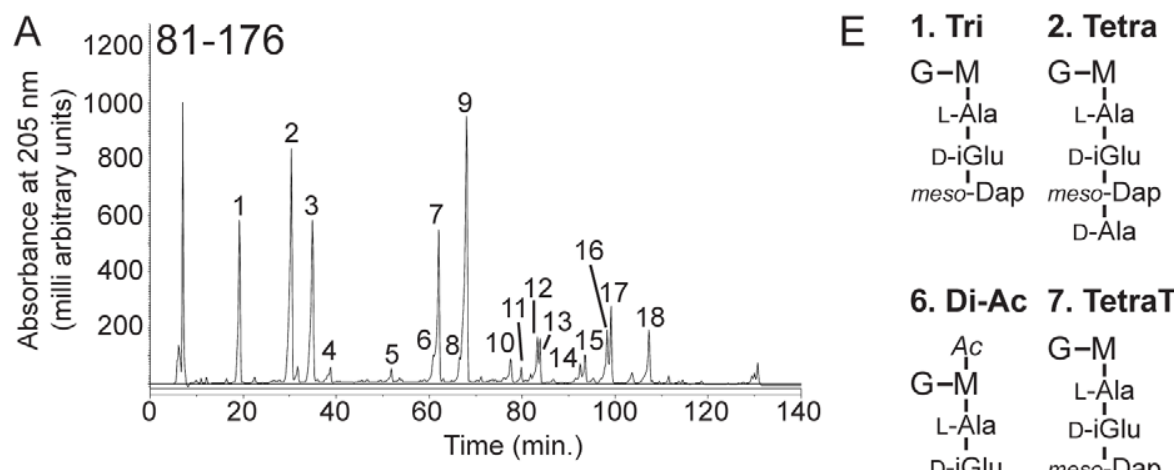
3. Di
G-M
L-Âla
I
D-iGlu

4. Tri-Ac

5. Tetra-Ac

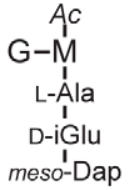

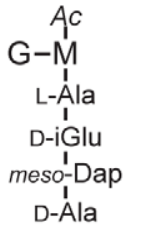

6. Di-Ac 7. TetraTri

8. PentaGly5

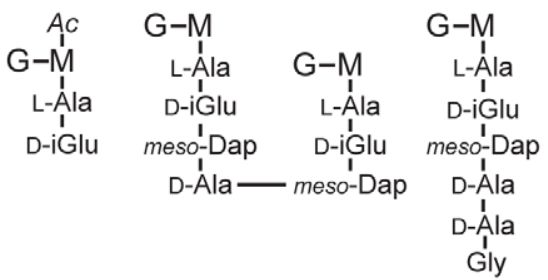

9. TetraTetra

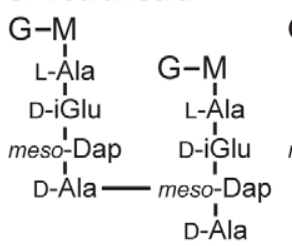

11. TetraTetraTri
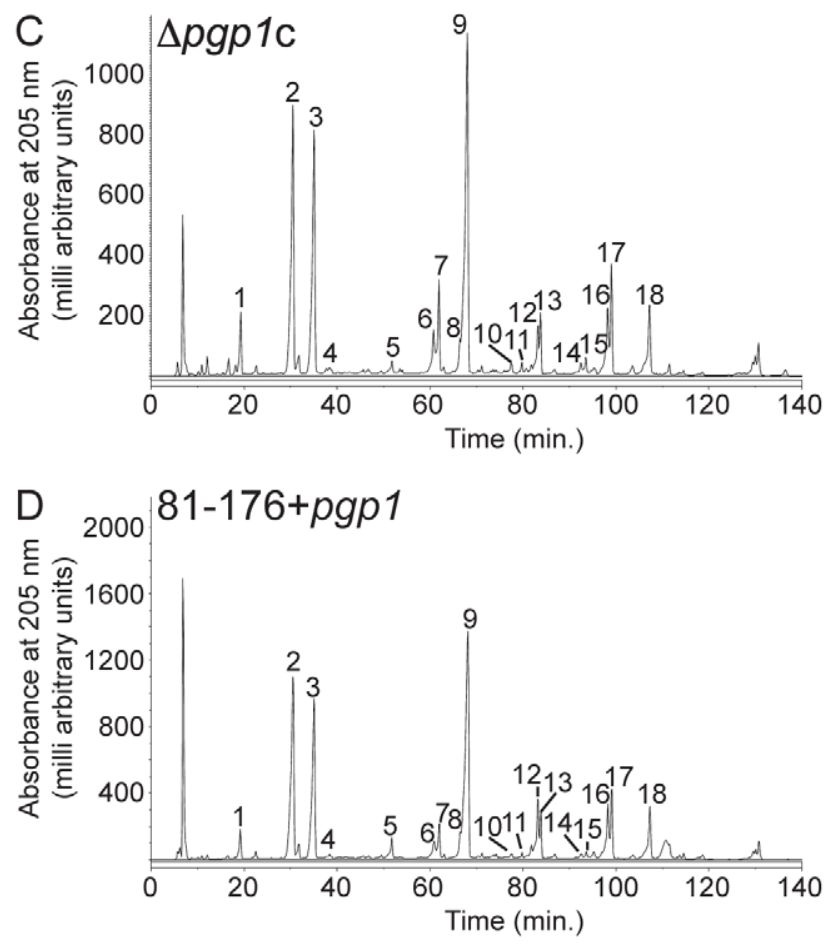

13. TetraTetraTetra

$\mathrm{G}-\mathrm{M}$

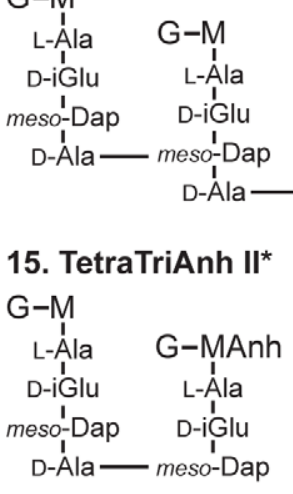

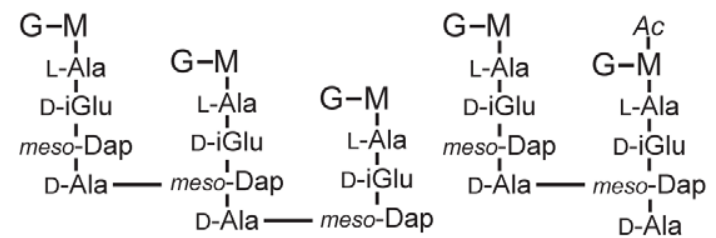

10. TetraTri-Ac*<smiles>[Al]C[As]</smiles>

D-íGlu L-Ála

meso'-Dap D-i'́lu

D-Alla - meso-Dap

\section{TetraTetra-Ac*}

14. TetraTriAnh I*

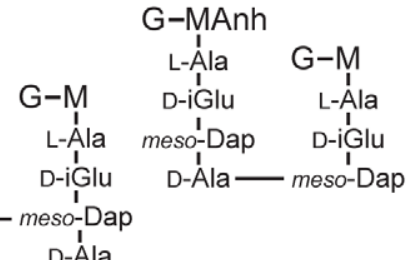

16. TetraTetraAnh I* G-MAnh

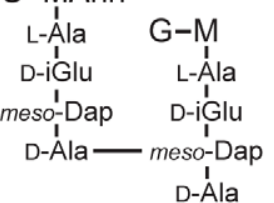

17. TetraTetraAnh II* 18. TetraTetraTetraAnh I*

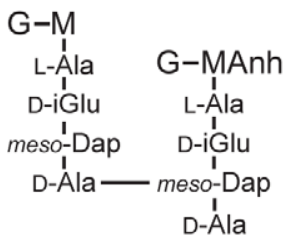

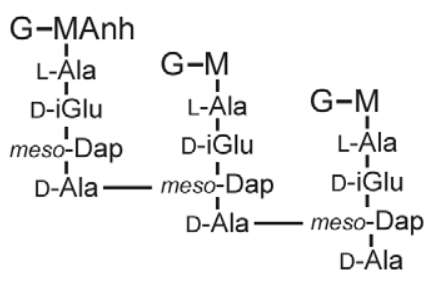

Figure 4. HPLC elution profile of $C$. jejuni muropeptides and proposed muropeptide structures. Purified PG was digested with cellosyl and the resulting muropeptides were reduced with sodium borohydride and separated on a Prontosil 120-3-C18 AQ reverse-phase column. HPLC profiles are shown for A, C. jejuni wild-type 81-176; B, $\Delta p g p 1$; C, the complement $\Delta p g p 1 c$; D, the pgp1 overexpressing strain, 81-176+pgp1. Peak numbers correspond to the main muropeptide peak fractions of $C$. jejuni 81-176 analyzed by LTQ-FT-MS (Table S3) to determine the structures shown in E. G, N-acetylglucosamine; M, reduced N-acetylmuramic acid; L-Ala, L-alanine; D-iGlu, D-isoglutamic acid; D-Glu, D-glutamic acid; meso-DAP, meso- 
diaminopimelic acid; Gly. Glycine; Ac, O-acetyl groups at the C-6 hydroxyl group of MurNAc; Anh, 1,6-anhydro group at MurNAc. The asterisk (*) indicates that it is not known on which MurNAc residue the modification occurs.

doi:10.1371/journal.ppat.1002602.g004

jejuni wild type PG stimulated Nod2; however, there was no statistically significant difference in activation levels between the wild type and $\Delta p g p 1$ mutant PG.

Secretion of interleukin-8 (IL-8) is increased by exposure of epithelial cells to $\Delta p g p 1$. It was previously shown that epithelial cells produce IL-8 in response to C. jejuni infection [29]. To examine the effect of the $\Delta p g p 1$ mutation on IL-8 secretion, the INT407 human epithelial cell line was infected with $C$. jejun $i$ wild type and $\Delta p g p 1$ strains, and the levels of IL-8 secreted into the supernatant were measured by ELISA (Figure 6E). The data shown in Figure $6 \mathrm{E}$ are representative of three separate experiments. IL-8 secretion from cells exposed to $\Delta p g p 1$ after $8 \mathrm{~h}$ was reproducibly higher than wild type, and in some experiments was statistically significant (not shown). After $24 \mathrm{~h}$, release of IL-8 in response to $\Delta p g p 1$ was 1.5 -fold higher than wild type and statistically significant in every experimental trial.

\section{Discussion}

Bacterial cell shape programs and their impact on biology are becoming increasingly well-characterized for model organisms like E. coli and Caulobacter crescentus [30,31]. However, studies linking bacterial shape and pathogenesis are in their infancy. This is the first report to address the morphogenesis program of the prevalent foodborne pathogen C. jejuni. Furthermore, apart from three annotated uncharacterized PBPs, no other C. jejuni PG-modifying enzymes have been identified. This is in spite of the fact that, as our study demonstrates, C. jejuni produces numerous muropeptide

Table 1. Summary of muropeptide composition of $C$. jejuni wild-type $81-176, \Delta p g p 1$ mutant, $\Delta p g p 1$ complement ( $\Delta p g p 1 \mathrm{c})$, and pgp1 overexpression (81-176+pgp1) strains, and the resultant $\Delta p g p 1$ PG profiles of Pgp1 activity assays consisting of $\Delta p g p 1 \mathrm{PG}$ incubated without enzyme, with Pgp1 in the presence of $\mathrm{ZnCl}_{2}$, and with Pgp1 without $\mathrm{ZnCl}_{2}$ but with EDTA.

\begin{tabular}{|c|c|c|c|c|c|c|c|}
\hline \multirow{3}{*}{ Muropeptide species } & \multicolumn{7}{|c|}{$\%$ Peak area ${ }^{1}$} \\
\hline & \multicolumn{4}{|c|}{ In C. jejuni strains } & \multicolumn{3}{|c|}{ Following incubation of $\Delta p g p 1$ PG } \\
\hline & $81-176$ & $\Delta p g p 1$ & $\Delta p g p 1 c$ & $\begin{array}{l}81-176+ \\
\text { pgp1 }\end{array}$ & $\begin{array}{l}\Delta p g p 1 \text { PG - } \\
\text { Pgp1 }\end{array}$ & $\begin{array}{l}\Delta p g p 1 \mathrm{PG}+ \\
\mathrm{Pgp} 1+\mathrm{ZnCl}_{2}\end{array}$ & $\begin{array}{l}\Delta p g p 1 \mathrm{PG}+\mathrm{Pgp} 1 \\
+ \text { EDTA }\end{array}$ \\
\hline Monomers (Total) & 43.3 & 43.4 & 43.1 & 42.1 & 41.1 & 45.4 & 52.4 \\
\hline $\mathrm{Di}$ & 14.5 & $5.9 *$ & $20.6 *$ & $18.4^{*}$ & 5.6 & 31.9* & 5.9 \\
\hline Tri & 10.5 & $34.4 *$ & 3.3* & $2.3^{*}$ & 32.6 & $2.0 *$ & 33.9 \\
\hline Tetra & 18.4 & $3.1 *$ & 19.2 & 21.5 & 2.9 & $11.5^{*}$ & $12.6 *$ \\
\hline Acetylated $^{2}$ & 3.3 & 5.1 & 4.2 & 4.0 & 0.7 & 2.2 & 2.1 \\
\hline Anhydro & & & & & 1.0 & $2.0 *$ & $3.0 *$ \\
\hline Dimers (Total) & 49.7 & 52.5 & 49.3 & 50.0 & 52.4 & 49.0 & 42.3 \\
\hline Tetra Tri & 14.7 & $37.0 *$ & $6.8^{*}$ & $3.7^{*}$ & 37.9 & 36.5 & 31.9 \\
\hline Tetra Tetra & 33.5 & $14.7 *$ & $40.8^{*}$ & 44.4* & 13.5 & 11.5 & 9.6 \\
\hline Tetra PentaGly ${ }^{5}$ & 1.5 & $0.7^{*}$ & 1.6 & $1.9^{*}$ & 0.9 & 0.9 & 0.8 \\
\hline Anhydro & 10.8 & 11.7 & 11.3 & 10.5 & 12.7 & $7.8^{*}$ & $5.8^{*}$ \\
\hline Acetylated $^{2}$ & 4.8 & 6.8 & 3.8 & 5.5 & 0.2 & 2.8 & 1.6 \\
\hline Trimers (total) & 6.9 & $4.2^{*}$ & 7.6 & 7.9 & 6.5 & 5.6 & 5.3 \\
\hline Tetra Tetra Tri & 0.8 & $1.9^{*}$ & $0.6^{*}$ & $0.3^{*}$ & 3.0 & 2.6 & 2.4 \\
\hline Tetra Tetra Tetra & 6.1 & $2.3^{*}$ & 7.0 & $7.6^{*}$ & 3.6 & 3.0 & 2.9 \\
\hline Dipeptides (Total) & 14.5 & $5.9 *$ & $20.6^{*}$ & $18.4^{*}$ & 5.6 & 31.9* & 5.9 \\
\hline Tripeptides (Total) & 18.1 & $53.6 *$ & $6.9^{*}$ & $4.2^{*}$ & 52.5 & 21.2* & 50.7 \\
\hline Tetrapeptides (Total) & 66.7 & $40.2 *$ & 71.6 & 76.5 & 41.4 & 46.5 & 43.0 \\
\hline Pentapeptides (Total) & 0.7 & $0.4^{*}$ & 0.8 & $1.0^{*}$ & 0.5 & 0.5 & 0.4 \\
\hline Acetylated (Total) ${ }^{2}$ & 5.7 & 8.5 & 6.1 & 6.7 & 0.8 & 3.6 & 2.9 \\
\hline Anhydro chain ends (Total) & 6.8 & 6.4 & 7.2 & 6.9 & 7.2 & $10.7^{*}$ & 10.1 \\
\hline Average chain length & 14.7 & 15.7 & 13.9 & 14.5 & 13.9 & $9.3^{*}$ & 9.9 \\
\hline Degree of cross-linkage & 29.5 & 29.0 & 29.7 & 30.2 & 30.5 & 28.2 & 24.7 \\
\hline$\%$ Peptides in cross-links & 56.7 & 56.6 & 56.9 & 57.9 & 58.9 & 54.6 & 47.6 \\
\hline
\end{tabular}

${ }^{1}$ Numbers represent the percent area of each muropeptide from Table S4 calculated to give a total of $100 \%$. Values indicated with an asterisk $(*)$ represent an equal to or greater than $20 \%$ difference in comparison to wild-type $81-176$ or $\Delta p g p 1$ PG to which no enzyme was added; bolded asterisked values $(*)$ indicate a greater than $30 \%$ change.

${ }^{2}$ Values for the percentage of O-acetylated species do not represent the true level of PG O-acetylation in these strains, as most O-acetyl groups are lost in the standard alkaline muropeptide reduction procedure used in this study.

doi:10.1371/journal.ppat.1002602.t001 


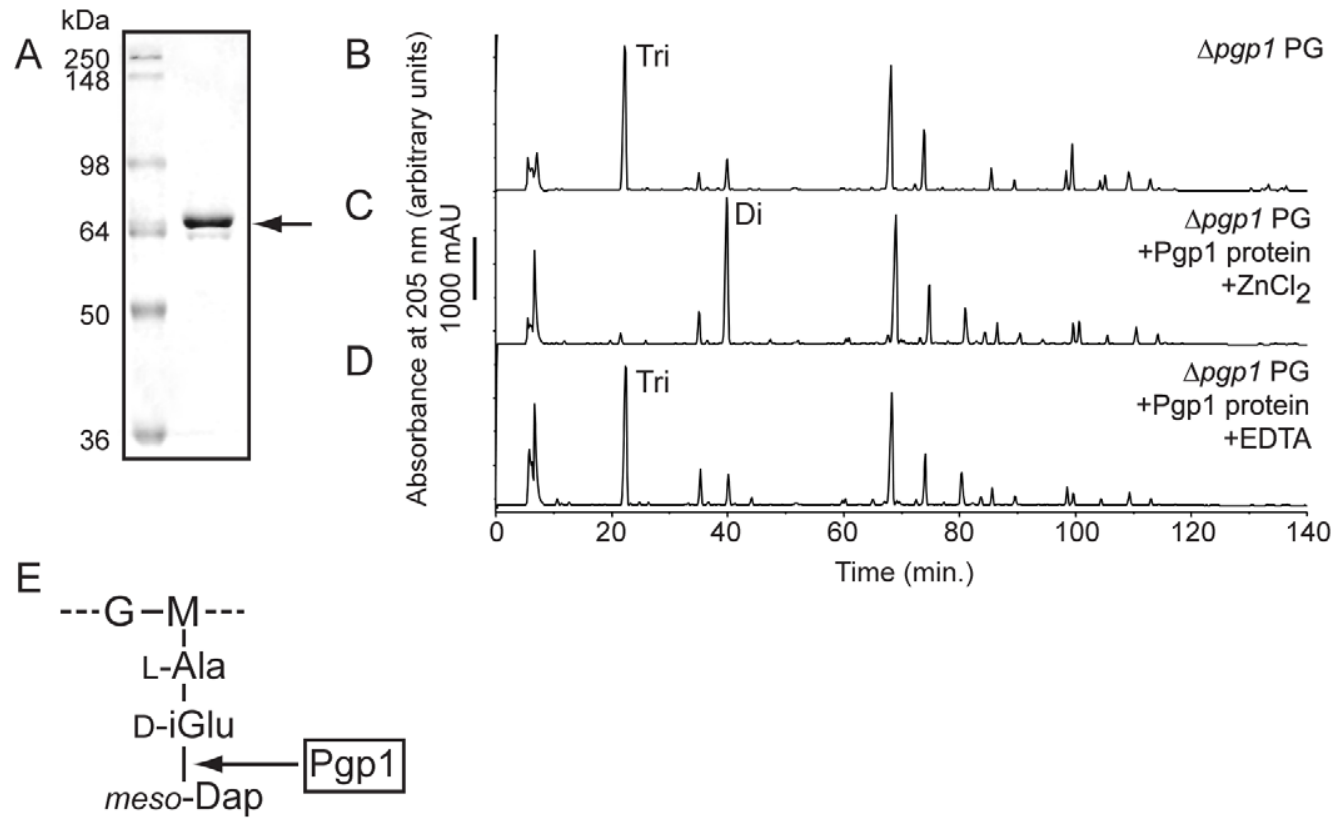

Figure 5. Pgp1 has metal-dependent DL-carboxypeptidase activity on $\Delta p g p 1$ PG, cleaving monomeric tripeptide disaccharides to dipeptides. A, SDS-PAGE analysis of affinity purified Pgp1 with a predicted molecular weight of $67.9 \mathrm{kDa}$, indicated by an arrow. HPLC chromatograms of B, purified $\Delta p g p 1$ PG; C, $\Delta p g p 1$ PG incubated with purified Pgp1 and $\mathrm{ZnCl}_{2}$; and D, $\Delta p g p 1$ PG with purified Pgp1 and EDTA. Peaks corresponding to monomeric disaccharide dipeptides and tripeptides are indicated. $\mathbf{E}$, a schematic diagram of the Pgp1 cleavage site indicated with an arrow. G, N-acetylglucosamine; M, reduced N-acetylmuramic acid; L-Ala, L-alanine; D-iGlu, D-isoglutamic acid; meso-DAP, meso-diaminopimelic acid.

doi:10.1371/journal.ppat.1002602.g005

species indicative of additional unidentified and potentially novel PG hydrolases.

Our identification and characterization of $p g p 1$ provides the first link between cell shape and PG in C. jejuni. Pgpl is conserved primarily in bacteria with curvature (Table S1). Although functions have not yet been ascribed for other putative shaperelated proteins in C. jejuni, it is of note that helical $\varepsilon$ - and $\delta$ proteobacteria also typically contain the elongase and cytoskeletal components MreB, MreC, and RodA, but not MreD or RodZ. As such, unique PG and morphogenesis programs are likely to be identified both within and among these organisms, which in turn will lend new insight into their biology and pathogenesis.

Enzyme assays demonstrated that Pgpl is a metal-dependent DLcarboxypeptidase cleaving monomeric disaccharide tripeptides to disaccharide dipeptides. This is consistent with Pgpl harboring an N-terminal M14 metallocarboxypeptidase domain present in two other PG dipeptidyl peptidases, E. coli $\mathrm{MpaA}$ and Bacillus sphaericus ENP1, which cleave tri- and tetrapeptides to dipeptides [32-35]. This also correlates with the reduction in dipeptides and increase in tripeptides in $\Delta p g p 1 \mathrm{PG}$. Decreased tetrapeptides in $\Delta p g p 1$ may be an indirect consequence of the increased level of tripeptides affecting activity of DD-carboxypeptidases, or an indirect effect on other PG hydrolases via disruption of a putative enzyme complex. Efforts to identify Pgpl binding partners that would support the latter hypothesis are underway. Our muropeptide analysis of $C$. jejuni 81-176 wild-type PG also revealed a muropeptide composition expected for a Gram-negative species, with several interesting differences from the related helical organism $H$. pylori $[19,36]$ and the rod-shaped E. coli $[14,24]$ (Table S5). For instance, unlike $H$. pylori, C. jejuni contains very low levels of pentapeptides, suggesting high DD-carboxypeptidase activity. C. jejuni $\mathrm{PG}$ also has a higher level of cross-linking than either other species, and a relatively short average glycan chain length.
With pgp1 being the first C. jejuni gene directly linked with helical morphology, it allowed for the first direct comparison between a helical wild type strain and an isogenic targeted rod-shaped mutant in critical aspects of $C$. jejuni pathogenesis and survival. The modest motility defect of the rod-shaped $\Delta p g p 1$ mutant may in part account for the modest biofilm defect [37-39]. Further corroborating the $p g p 1$-biofilm connection are our observations that $p g p 1$ is up-regulated in the hyperbiofilm-forming $\Delta c p r S$ strain (S. Svensson and E. C. Gaynor, unpublished) and that $\Delta p g p 1$ is hyporeactive to CFW [10]; the latter observation in turn continues to support a link between $C$. jejuni CFW reactivity and key biological and pathogenic processes. Isolated $\mathrm{PG}$, which has a $\beta 1-4$ disaccharide backbone, binds to CFW (E. Frirdich and E. C. Gaynor, unpublished), suggesting that changes in $\mathrm{PG}$ architecture in $\Delta p g p 1$ may account for decreased CFW reactivity. However, as PG isolated from both wild type and mutant strains bound CFW equally well, a related explanation is that PG alterations affect the accessibility of CFW to binding sites on periplasmic PG molecules.

The $\Delta p g p 1$ mutant also allowed us to explore roles for shape and PG composition on host interactions. Surprisingly, the $\Delta p g p 1$ mutant was not defective for host cell attachment or invasion in vitro and even displayed a slight increase in short-term intracellular survival. Increasing the viscosity of the media did not affect the ability of the mutant to invade epithelial cells (Figure S2). It is of note that although attachment and invasion to host cells increased for some C. jejuni strains in higher viscosity medium [28], this was not the case for our highly invasive wild-type strain 81-176, suggesting varying invasion programs among different $C$. jejuni strains.

Intracellular $C$. jejuni was previously shown to induce host epithelial cell inflammatory responses via activation of the cytoplasmic Nod receptors [40,41], which recognize distinct PG muropeptide molecules. The minimal molecule recognized by 
A Chick colonization
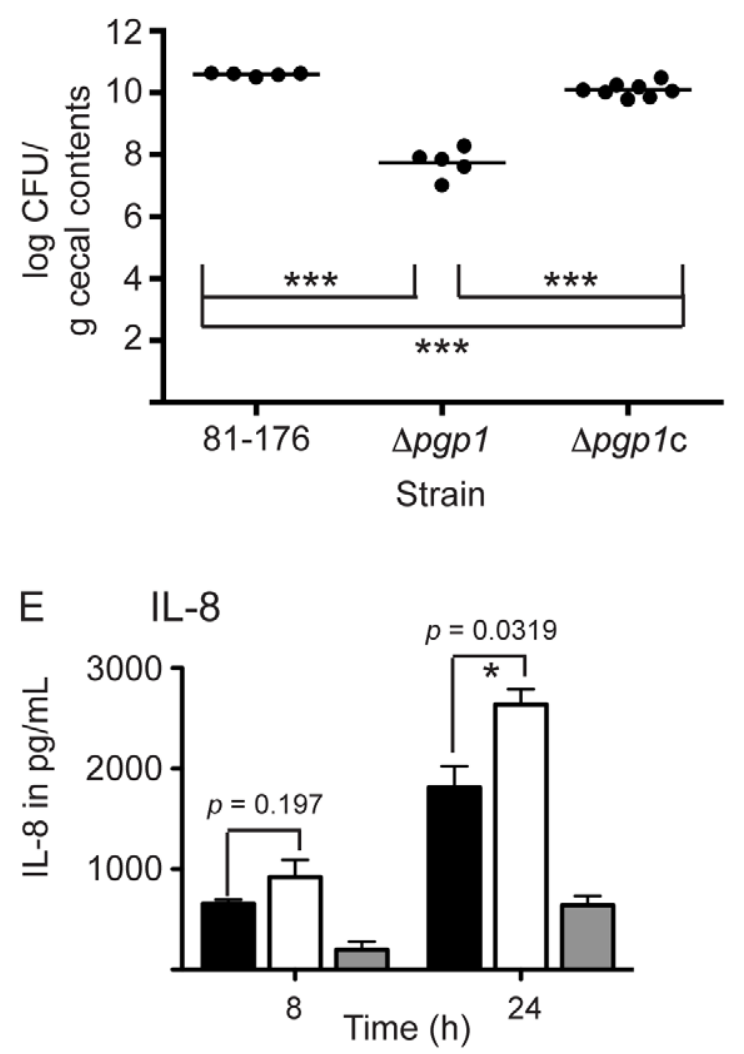

81-176

$\square \Delta p g p 1$

$\square$ Uninfected
B hNod1

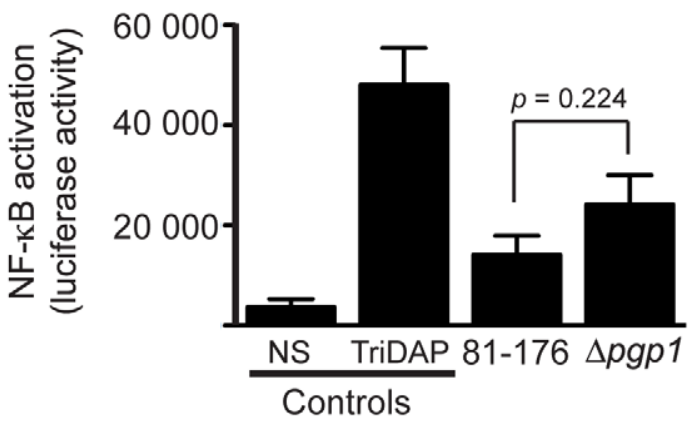

$\mathrm{C}$
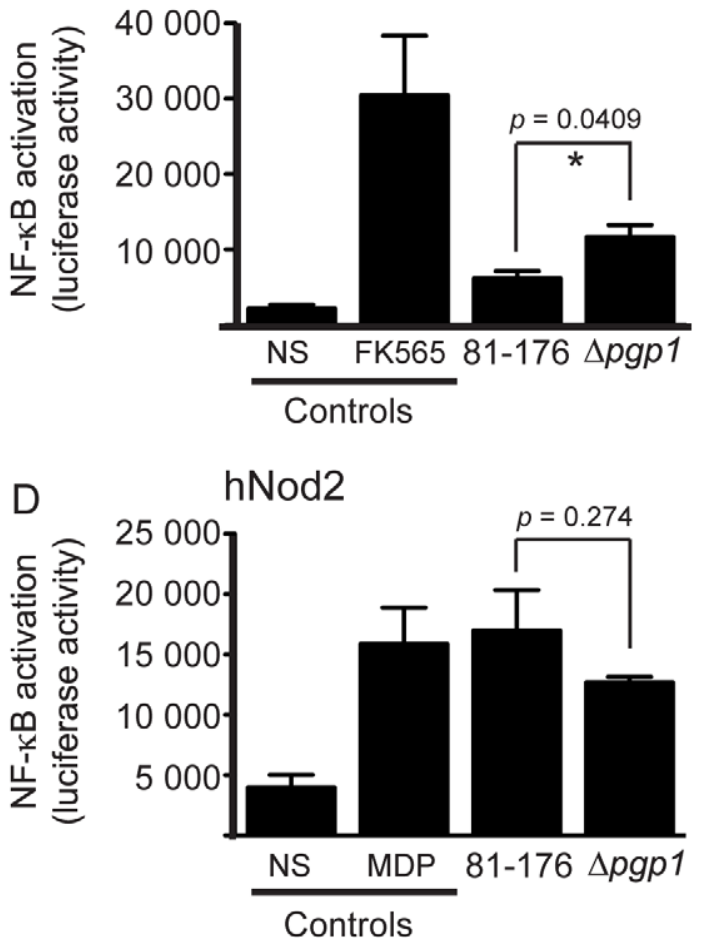

Figure 6. The role of cell shape and PG composition on host related phenotypes. A, $\Delta p g p 1$ is defective for chick colonization. Each point represents the log CFU/g cecal contents of an individual chick 6 days following infection with $10^{4}$ CFUs of the indicated C. jejuni strains. The geometric mean is denoted by a black bar. B-D, to assay the ability of C. jejuni wild type and $\triangle p g p 1$ PG to activate Nod proteins, human embryonic kidney cells (HEK293T) were co-transfected with either C. jejuni 81-176 or $\Delta p g p 1 \mathrm{PG}$ at $0.1 \mu \mathrm{g} / \mathrm{mL}$, vectors for a NF-kB luciferase reporter, and either human Nod1 (B, hNod1), mouse Nod1 (C, mNod1) or human Nod2 (D, hNod2). Nod activation was determined by measuring the activity of the NFKB luciferase reporter in comparison to the non-stimulated (NS) negative control. Positive controls used were TriDAP, FK565, and MDP. Data represent the mean \pm SEM of three independent experiments. E, Deletion of pgp 1 increases IL-8 secretion in the INT407 epithelial cell line. Quantification of IL8 levels was performed by ELISA. Data represent the mean \pm SEM of three independent experiments. The asterisk $(*)$ indicates a statistically significant difference using the unpaired Student's t-test, with * or ${ }^{* * *}$ indicating $p<0.05$ or $p<0.001$, respectively.

doi:10.1371/journal.ppat.1002602.g006

hNod2 is muramyl dipeptide (MDP), a structure common to PG from both Gram-negative and Gram-positive organisms [42]. hNodl and mNodl recognize DAP-containing muropeptides restricted to Gram-negative organisms. hNodl exhibits a preference for tripeptides and mNodl for tetrapeptides; however mNodl also, to a lesser degree, recognizes DAP-containing tripeptides ([43]; J. Lee and S. Girardin, unpublished). Luciferase assays are a sensitive method to probe the capacity of a PG preparation to trigger Nod1 or Nod2 and provide complementary information to PG compositional data by HPLC and MS analyses. Using these assays, only mNodl exhibited a statistically significant difference in activation by $\Delta p g p 1 \mathrm{PG}$ compared to wild type. It is possible that C. jejuni modifies its PG in a manner that affects Nod signaling, as modifications of the PG backbone have been shown to affect how PG fragments are sensed by host cell receptors [44]. This poses an interesting question for future work. Our data also indicate that wild-type PG can activate hNod2, consistent with findings by Al-Sayeqh et al. (2010) who also showed NF- $\kappa$ B activation in HEK293T cells transfected with Nod2 and infected with live C. jejuni. While Zilbauer et al. (2007) did not observe $C$. jejuni activation of Nod2, this may reflect differences between cell lines used in these assays, and/or differences in reporter sensitivity.

Nod activation is an important aspect of innate immunity against $C$. jejuni $[40,41]$; however, the mechanism by which $C$.jejuni 
PG fragments may reach the cytosol to activate Nodl and/or Nod2 has not been elucidated. C. jejuni can be internalized into intestinal epithelial cells, surviving within an intracellular membrane-bound compartment known as the $C$. jejuni-containing vacuole (GCV) [45]. An oligopeptide transporter expressed in the early endosome has been implicated in the transport of Nod ligands from the endosome to the cytoplasm in HEK293T cells [46]; a similar system could allow cytoplasmic delivery of PG fragments from C. jejuni in the CCV. Another possibility is that during growth in the extracellular environment $C$. jejuni may shed part of its PG, as shown for other bacteria [44,47,48]; released Nodl and Nod2-stimulatory molecules could then be transported to the cytoplasm by oligopeptide transporters or taken up by phagocytosis or clathrin-dependent endocytosis and transported to the cytosol to activate Nods [44,49-51]. Bacterial outer membrane vesicles may also play a role in delivering $C$. jejuni Nod ligands to the cytoplasm [52].

Production of IL-8 and other proinflammatory mediators by intestinal epithelial cells infected with $C$. jejuni is thought to be key to the development of diarrhea and clearance of infection. Zilbauer et al. (2007) suggested that C. jejuni Nodl activation is the primary signaling event required for IL-8 expression in Caco-2 intestinal epithelial cells. However, other work indicates that $C$. jejuni-induced IL-8 secretion can be triggered by other pathways in addition to the activation of Nodl, such as through Toll-like receptors (TLRs) and a pathway independent of Nods and TLRs that has yet to be identified $[40,53-58]$. Thus while the increase in IL-8 secretion in response to $\Delta p g p 1$ may be due to the modest increase in hNodl activation observed in our luciferase assays, it cannot be ruled out that deletion of $p g p 1$ leads to a change in another, as-yet unidentified factor stimulating IL-8 expression. Future work is planned to address these hypotheses.

Our colonization data are in agreement with the longstanding hypothesis that the corkscrew morphology of C. jejuni is critical for burrowing into the mucus layer; however, the impact of shape and PG on colonization may be multifactorial. For instance, motility is a key factor in colonization [59-64], thus the $\Delta p g p 1$ colonization defect may in part be due to its decreased motility. However, a $\Delta$ carB mutant with a similar motility defect was not deficient for chick colonization (Figure S1). When the strongly colonizing $C$. jejuni strain 305/94 was re-isolated from chickens, it displayed a more pronounced motility defect than $\Delta p g p 1$ despite having normal flagella, and had lost its helical shape, exhibiting a similar straight morphology as $\Delta p g p 1$ [65]. It is intriguing to hypothesize that not only shape, but also the underlying structure of the PG may play an important role in colonization. We have found that a straight phenotype can arise from various changes in muropeptides based on preliminary analysis of other straight mutants identified in our laboratory (E. Frirdich, J. Vermeulen, and E. C. Gaynor, unpublished). PG changes or changes resulting from the loss of $p g p 1$ could cause as-yet uncharacterized alterations to the cell surface affecting the ability of $C$. jejuni to survive in the chicken cecum, or affect host cell interactions and stimulation of innate immune receptors. Our understanding of the chicken innate immune system and how it responds to $C$. jejuni is in its infancy. The chicken genome encodes Nod1 but not Nod2, although chickens possess an ortholog of the NLRP3/NALP3 Nod-like receptor that is similar to Nod2 and also binds MDP [66,67]. NLRP3 may substitute for Nod2 in chickens. Further insight into mechanisms by which C. jejuni survives commensally in the chicken cecum requires additional studies of these and other innate immune system factors.

Identification and characterization of $p g p 1$ provides a critical first step in understanding how shape and PG modifications impact C. jejuni pathogenesis. However, the shape program itself in C. jejuni is likely to be somewhat complicated. For instance, to the best of our knowledge, Pgpl is the only PG modifying enzyme to date where overexpression causes cell straightening, indicating that the precise dose of Pgpl is important for maintenance of morphology. One interpretation of this finding is that the proper ratio of monomeric tripeptides to dipeptides, which is disrupted in both the $\Delta p g p 1$ mutant and $p g p 1$-overexpressing strains, may be required for proper shape determination. It is also possible that excess Pgpl could, as suggested for loss of Pgpl above, indirectly affect other PG hydrolases by disrupting the stoichiometry of a putative PG biosynthetic/modification complex. Additional complexities in the shape program are evidenced by reports of straight Campylobacter strains in the literature for which the morphological change has not yet been attributed to mutations in specific gene product(s). For instance, some C. jejuni flagellar mutants appeared to have a straight morphology [68-70]; however, other mutants with lesions in the same flagellar genes remained helical ([71,72]; E. Frirdich and E. C. Gaynor, unpublished). Two reports also cited that passage through the chicken gut or chick embryos resulted in straight C. jejuni isolates [65,73]. Conversely, laboratory passage has led to the isolation of poorly colonizing rod-shaped $C$. jejuni and C. coli strains [74,75]. In the 11168-GS (straight) and 11168-O (helical) strains of the 2004 study, sequence and expression levels of $p g p 1$ were found to be identical (E. Frirdich and E. C. Gaynor, unpublished). Collectively, this suggests not only that genes other than $p g p 1$ affecting morphology remain to be discovered, but also that mechanisms such as phase variation and/ or epigenetics may be involved.

The pgp1 homolog in H. pylori (named csd4) was identified in a screen for cell shape mutants and is described by Sycuro et al. [22]. Morphology, PG profile, and enzymatic activity indicate conserved functions for the gene products in both organisms. While some enzymes and their effects on morphology are conserved between these related helical bacteria, there are also likely to be differences in the overall PG remodeling and shape determining programs, particularly given their very different wildtype muropeptide profiles.

The $\Delta p g p 1$ mutant will be a valuable tool to continue to study the effects of the loss of $C$. jejuni helical shape on its biology and pathogenesis. So far, pgp1 has been found to be important for all aspects of the C. jejuni life cycle. As this study represents the first identification of a gene involved in C. jejuni helical shape and of a role for PG in shape determination, it will also provide the basis for work characterizing additional enzymes involved in C. jejuni PG biosynthesis and shape determination. These studies have now been made easier by the availability of PG structural data for the wild-type C. jejuni strain 81-176 published as part of this work. Future detailed biochemical and structural studies on Pgpl will also provide interesting insight into the function of this key protein in C. jejuni physiology.

\section{Materials and Methods}

\section{Ethics statement}

Animal experiments were carried out in strict accordance with the University of Michigan Committee on Use and Care of Animals (UCUCA). Animal infection and euthanasia protocols were approved by the University of Michigan UCUCA and assigned approval number 10462. Oral gavage was carried out under humane guidelines using an approved protocol judged not to cause distress or harm to the animals. Euthanasia was carried out under humane guidelines using a lethal dose of isofluorane. All animal use procedures are in compliance with University 
guidelines, State and Federal regulations, and the standards of the National Institutes of Health Guide for the Care and Use of Laboratory Animals. The University of Michigan Animal Welfare Assurance Number on file with the NIH Office of Laboratory Animal Welfare (OLAW) is A3114-01, and the University is fully accredited by the Association for the Assessment and Accreditation of Laboratory Animal Care International (AAALAC, Intl.).

\section{Bacterial strains and growth conditions}

Bacterial strains and plasmids used in this study and their construction are described in Text S1. C. jejuni strains were grown at $38^{\circ} \mathrm{C}$ in Mueller-Hinton (MH; Oxoid) broth or $8.5 \%(\mathrm{w} / \mathrm{v})$ agar supplemented with vancomycin $(10 \mu \mathrm{g} / \mathrm{mL})$ and trimethoprim $(5 \mu \mathrm{g} / \mathrm{mL})$ (unless otherwise indicated) under microaerobic/ capnophilic conditions $\left(6 \% \mathrm{O}_{2}, 12 \% \mathrm{CO}_{2}\right)$ in a Sanyo tri-gas incubator for plates or using the Oxoid CampyGen system for broth cultures. Growth media were supplemented with chloramphenicol $(\mathrm{Cm} ; 20 \mu \mathrm{g} / \mathrm{mL})$ or kanamycin $(\mathrm{Km} ; 50 \mu \mathrm{g} / \mathrm{mL})$, where appropriate. E. coli strains used for plasmid construction were grown at $37^{\circ} \mathrm{C}$ in Luria-Bertani (LB; Sigma) broth or $7.5 \%$ agar $(\mathrm{w} / \mathrm{v})$ and supplemented with ampicillin $(100 \mu \mathrm{g} / \mathrm{mL}), \mathrm{Cm}$ $(15 \mu \mathrm{g} / \mathrm{mL})$, or $\mathrm{Km}(25 \mu \mathrm{g} / \mathrm{mL})$, as necessary.

\section{RNA extraction, cDNA synthesis and RT-qPCR}

RNA was extracted from log phase broth bacteria (OD 0.3), and cDNA was generated from the RNA, as described previously $[74,76]$. The expression ratio of $p g p 1$ was determined relative to the C. jejuni gyrA gene encoding DNA gyrase subunit A. The primer and TaqMan probe sequences used for qPCR are described in Text S1. Each qPCR reaction mixture consisted of $25 \mathrm{ng}$ of cDNA, $950 \mathrm{nM}$ of each primer, $250 \mathrm{nM}$ TaqMan probe, and $10 \mu \mathrm{l} 2 \times$ TaqMan Gene Expression Master Mix (Applied Biosystems) in a total volume of $20 \mu \mathrm{l}$. Duplicate reactions for the gene of interest and the housekeeping gene were run in a Stratagene Mx3000P real-time PCR system for $2 \mathrm{~min}$ at $60^{\circ} \mathrm{C}$, $10 \mathrm{~min}$ at $95^{\circ} \mathrm{C}$, and then 40 cycles of $15 \mathrm{~s}$ at $95^{\circ} \mathrm{C}$ and $1 \mathrm{~min}$ at $60^{\circ} \mathrm{C}$. The quantitative PCR cycle threshold $\left(C_{T}\right)$ results were analyzed by the comparative $C_{T}$ method $\left(\Delta \Delta C_{T}\right.$ method).

\section{Calcofluor white (CFW) mutant screen}

The C. jejni 81-176::solo $\left(\mathrm{Km}^{\mathrm{R}}\right)$ and C. jejuni 81-176::picard $\left(\mathrm{Cm}^{\mathrm{R}}\right)$ Tn libraries (Tn library construction is described in Text $\mathrm{Sl}$ ) and were screened on CFW, as described previously [10].

\section{Microscopy}

Transmission electron microscopy (TEM) was carried out on $18 \mathrm{~h}$ broth cultures. Samples were fixed in a final concentration of $2.5 \%$ (v/v) of gluteraldehyde for 2-3 h on ice. Cells were then harvested, resuspended in an equal volume of $\mathrm{H}_{2} \mathrm{O}$, and stored at $4^{\circ} \mathrm{C}$. For imaging, $2 \mu \mathrm{L}$ of bacteria was spotted onto parafilm to which $4 \mu \mathrm{L}$ of $0.5 \%$ uranyl acetate was added for $1 \mathrm{~min}$. A formavar-carbon film on 300 mesh copper grid (Canemco, Lakefield, Quebec, Canada) was added to the bacteria-uranyl acetate spot for $2 \mathrm{~min}$. The grid was then removed, dried, washed ten times in sterile water, dried again and visualized on a Hitachi H7600 TEM equipped with a side mount AMT Advantage (1 mega-pixel) CCD camera (Hamamatsu ORCA) at the UBC Bioimaging facility (The University of British Columbia, Vancouver, BC, Canada).

\section{Phenotypic characterization: CFW, motility, and biofilm formation}

Phenotypic assays were carried out with strains grown in shaking MH-TV broth or biphasic cultures grown for $18 \mathrm{~h}$. CFW fluorescence was assayed as described previously [10]. For motility, cultures were diluted to an $\mathrm{OD}_{600}$ of 0.2 in MH-TV and $2 \mu \mathrm{l}$ was point inoculated into $\mathrm{MH}-\mathrm{TV}$ plates containing $0.4 \%$ agar. Plates were incubated for $20 \mathrm{~h}$ and the halo diameter was measured. Biofilm formation was assayed using crystal violet as described previously [11] with the exception that the absorbance was measured at $570 \mathrm{~nm}$.

\section{Peptidoglycan isolation and muropeptide analysis}

C. jejuni strains were passaged once from frozen stocks and then passaged to 20-25 MH plates and grown for $20 \mathrm{~h}$ to obtain logphase bacteria at a final OD of 200-600. Cells were collected into cold MH broth by scraping, harvested by centrifugation at $8000 \times$ $\mathrm{g}$ for $15 \mathrm{~min}$ and then resuspended in $6 \mathrm{~mL}$ ice cold $\mathrm{H}_{2} \mathrm{O}$. Cells were lysed by dropwise addition to $6 \mathrm{~mL} \mathrm{8 \%} \mathrm{SDS} \mathrm{boiling} \mathrm{under}$ reflux. PG was purified from the cell lysate, digested with the muramidase cellosyl (kindly provided by Hoechst, Frankfurt, Germany), and the resulting muropeptides were reduced with sodium borohydride and separated by HPLC as described [77]. Muropeptide fractions were collected, concentrated in a SpeedVac, acidified by $1 \%$ trifluoroacetic acid, and analysed by offline electrospray mass spectrometry on a Finnigan LTQ-FT mass spectrometer (ThermoElectron, Bremen, Germany) at the Newcastle University Pinnacle facility as described [25]. Muropeptide structures were assigned based on (i) comparison with retention times of known muropeptides from $H$. pylori, Caulobacter crescentus and E. coli and (ii) the obtained MS data (Table S3) and MS/MS fragmentation patterns (not shown).

\section{Expression, purification and enzymatic activity of Pgp1}

The C.jejuni 81-176 pgp1 gene was cloned for expression in E. coli without its signal peptide (amino acids 16-464 of the protein) in frame with the thioredoxin- and His-tag of the pET32a vector to give plasmid pEF46. A detailed description of the cloning of the expression construct, and the expression and purification protocol is included in Text S1. For enzyme assays, the purified protein was dialysed against $0.05 \mathrm{M}$ Tris-Cl, $\mathrm{pH} 7.5$ containing $0.01 \mathrm{M} \mathrm{ZnCl}_{2}$, $0.3 \mathrm{M} \mathrm{NaCl}$ and $20 \%$ glycerol. Purified $\Delta p g p 1 \mathrm{PG}(1.0 \mathrm{mg} / \mathrm{ml})$ was incubated with Trx-His 6 -Pgpl $(5 \mathrm{mM})$ in $0.02 \mathrm{M} \mathrm{NaH}_{2} \mathrm{PO}_{4}$, $\mathrm{pH} 4.8,0.005 \mathrm{M} \mathrm{ZnCl}_{2}$, and $0.1 \mathrm{M} \mathrm{NaCl}$ for $4 \mathrm{~h}$ at $37^{\circ} \mathrm{C}$ on a Thermomixer at $750 \mathrm{rpm}$. A control sample received no enzyme and another enzyme sample contained $0.01 \mathrm{M}$ EDTA and no $\mathrm{ZnCl}_{2}$. The samples were incubated with $10 \mu \mathrm{g}$ of cellosyl (Hoechst, Frankfurt am Main, Germany) for $1 \mathrm{~h}$, boiled for $10 \mathrm{~min}$ and centrifuged at room temperature for $15 \mathrm{~min}$ at $16000 \mathrm{~g}$. The muropeptides present in the supernatant were reduced with sodium borohydride and analyzed by HPLC, as described [24].

\section{Chick colonization}

Chick colonization was performed as described previously $[61,76]$, with an infective dose of $10^{4} \mathrm{CFU}$. Chicken experiments were carried out under protocol \#10462 approved by the University of Michigan Committee on Care and Use of Animals (UCUCA).

\section{In vitro invasion and intracellular survival in epithelial and macrophage cell lines}

The human epithelial cell lines T84, Caco-2 and INT407 and the murine RAW 264.7 and human Thp-1 macrophage cell lines were used for C. jejuni infections. Carboxymethylcellulose (CMC) was added to the tissue culture media to increase viscosity. A detailed description of the tissue culture infections is included in Text S1. 
Epithelial cell responses \& Nod activation assays

Luciferase asssays were performed as previously described [46]. Briefly, HEK293T cells were transfected overnight with $75 \mathrm{ng}$ of

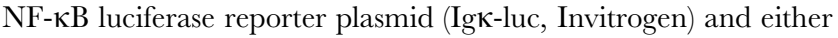
human Nodl (hNod1, $3 \mathrm{ng}$ ), mouse Nodl (mNodl, $0.1 \mathrm{ng}$ ), or human Nod2 (hNod2, $0.1 \mathrm{ng}$ ). The empty vector (pcDNA3.1, Invitrogen) was used to balance the transfected DNA concentration. At the same time, either C. jejuni 81-176 or $\Delta p g p 1 \mathrm{PG}$ muropeptides at $0.1 \mu \mathrm{g} / \mathrm{mL}$ were added, and the NF- $\kappa \mathrm{B}-$ dependent luciferase activation was then measured following 18$24 \mathrm{~h}$ of co-incubation. Positive controls were TriDAP (tripeptide L-Ala- $\gamma$-D-Glu-meso-DAP, $5 \mu \mathrm{g} / \mathrm{ml}$ ), FK 565 (a synthetic immunostimulant tetrapeptide, heptanoyl-D-glutamyl-meso-DAP-D-alanine, $5 \mathrm{ug} / \mathrm{ml}$ ), and MDP (muramyldipeptide, $10 \mu \mathrm{g} / \mathrm{ml}$ ) for $\mathrm{hNodl}$, mNodl, and Nod2 assays, respectively. Data are representative of three independent experiments.

\section{Interleukin-8 quantification}

The INT407 human epithelial cell line was seeded at approximately $1 \times 10^{5}$ cells $/ \mathrm{ml}$ in MEM supplemented with $10 \%$ FBS into 24-well tissue culture plates and allowed to grow for 20$24 \mathrm{~h}$ prior to infection. The cells were washed three times with MEM and either left uninfected or infected with either $C$. jejuni wild-type strain 81-176 or $\Delta p g p 1$ at an O.D. 600 of $0.002 / \mathrm{mL}$ taken from an $18 \mathrm{~h}$ shaking broth culture. Supernatants were collected after $8 \mathrm{~h}$ and $24 \mathrm{~h}$, centrifuged for $10 \mathrm{~min}$ to pellet residual cells and bacteria, and frozen at $-80^{\circ} \mathrm{C}$ until assayed. The concentration of IL-8 present in the supernatants was measured by the human IL-8 ELISA kit (Invitrogen, Camarillo, CA).

\section{Supporting Information}

Figure $\mathrm{S} 1 \quad G$. jejuni $\Delta c a r B$ has a motility defect, but is unaffected for chick colonization. A, negatively stained TEM images of $\Delta$ car $B$ showing the full-length flagella and helical morphology. B, $\Delta$ car $B$ exhibits a slight motility defect, as assayed by measuring halo diameters in soft agar plates. Standard error of the mean was calculated from 8 measurements. The asterisks (***) indicate a statistically significant difference $(p<0.001)$ using the unpaired Student's t-test. C, $\Delta$ carB shows no defect for chick colonization. Each point represents the $\log \mathrm{CFU} / \mathrm{g}$ cecal contents of an individual chick 6 days following infection with $10^{4}$ CFUs of the indicated C. jejuni strains. The geometric mean is denoted by a black bar.

(TIF)

Figure S2 G. jejuni $\Delta p g p 1$ shows slightly enhanced intracellular survival, but no defect in invasion in the presence of carboxymethylcellulose (GMC). A, a gentami-

\section{References}

1. Park SF (2002) The physiology of Campylobacter species and its relevance to their role as foodborne pathogens. Int J Food Microbiol 74: 177-188.

2. Lee MD, Newell DG (2006) Campylobacter in poultry: filling an ecological niche. Avian Dis 50: 1-9.

3. Newell DG, Wagenaar JA (2000) Poultry infections and their control at the farm level. In: Nachamkin I, Blaser MJ, eds. Campylobacter. Washington, D. C.: American Society for Microbiology. pp 497-509.

4. Black RE, Levine MM, Clements ML, Hughes TP, Blaser MJ (1988) Experimental Campylobacter jejuni infection in humans. J Infect Dis 157: 472-479.

5. Blaser MJ, Engeberg J (2008) Clinical aspects of Campylobacter jejuni and Campylobacter coli infections. In: Szymanski CM, Nachamkin I, Blaser MJ, eds. Campylobacter, 3rd Edition. Washington, DC: ASM Press. pp 99-122.

6. Hofreuter D, Tsai J, Watson RO, Novik V, Altman B, et al. (2006) Unique features of a highly pathogenic Campylobacter jejuni strain. Infect Immun 74: 4694 4707.

7. Parkhill J, Wren BW, Mungall K, Ketley JM, Churcher C, et al. (2000) The genome sequence of the food-borne pathogen Campylobacter jejuni reveals hypervariable sequences. Nature 403: 665-668. cin $(\mathrm{Gm})$ protection assay was used to assess the invasion and intracellular survival ability of $\Delta p g p 1$ in Caco-2 intestinal epithelial cells. Gm was added 3 h post-infection with bacterial strains. After $2 \mathrm{~h}$ the $\mathrm{Gm}$ was washed off and the cells were incubated with fresh MEM containing 3\% FBS and a low dose of Gm. B, infections were carried out in the presence of MEM containing $1 \%$ and $2 \%$ CMC to examine the ability of $\Delta p g p 1$ to invade INT407 epithelial cells in higher viscosity media. CFUs were determined for each well by lysing the cells with water and plating the dilutions onto MH-TV plates. Standard errors of the mean were calculated from triplicate readings and are representative of three independent experiments. The asterisk $\left(^{*}\right)$ indicates a statistically significant difference $(p<0.05)$ using the unpaired Student's t-test.

(TIF)

Table S1 BLAST results for the $G$. jejuni 81-176 1344/ pgp1 gene product.

(DOC)

Table S2 Summary of $\Delta p g p 1$ phenotypes tested that were similar to wild type.

(DOC)

Table S3 Molecular mass of $C$. jejuni 81-176 muropeptides (reduced form) separated by HPLG and analyzed by LTQ-FT-MS.

(DOG)

Table S4 Muropeptide compositional analysis used to determine the values in Table 1 .

(DOG)

Table S5 PG muropeptide composition of $G$. jejuni wildtype strain 81-176 in comparison to $H$. pylori and $E$. coli. (DOC)

Text S1 Supplemental materials and methods. (DOG)

\section{Acknowledgments}

We thank Jenny Vermeulen for technical support and Joe Gray of the Pinnacle laboratory of Newcastle University for MS analysis. We thank Dave Hendrixson and Dave Lampe for providing reagents, and Laura Sycuro and Nina Salama for sharing results prior to publication.

\section{Author Contributions}

Conceived and designed the experiments: EF JB CA JLJE LDG VJD SEG WV ECG. Performed the experiments: EF JB CA JL JE LDG. Analyzed the data: EF JB CA JL JE LDG VJD SEG WV ECG. Contributed reagents/materials/analysis tools: VJD SEG WV ECG. Wrote the paper: EF JB CA JL JE LDG VJD SEG WV EGG.
8. Rattee ID, Breur MM (1974) The Physical Chemistry of Dye Absorption. New York: Academic Press. pp 180-182.

9. Wood PJ (1980) Specificity in the interaction of direct dyes with polysaccharides. Carbohydr Res 85: 271-287.

10. McLennan MK, Ringoir DD, Frirdich E, Svensson SL, Wells DH, et al. (2008) Campylobacter jejuni biofilms up-regulated in the absence of the stringent response utilize a calcofluor white-reactive polysaccharide. J Bacteriol 190: 1097-1107.

11. Naito M, Frirdich E, Fields JA, Pryjma M, Li J, et al. (2010) Effects of sequential Campylobacter jejuni 81-176 lipooligosaccharide core truncations on biofilm formation, stress survival, and pathogenesis. J Bacteriol 192: 2182-2192.

12. Vollmer W, Blanot D, de Pedro MA (2008) Peptidoglycan structure and architecture. FEMS Microbiol Rev 32: 149-167.

13. Typas A, Banzhaf M, van den Berg van Saparoea B, Verheul J, Biboy J, et al (2010) Regulation of peptidoglycan synthesis by outer-membrane proteins. Cell 143: 1097-1109.

14. Vollmer W, Bertsche U (2008) Murein (peptidoglycan) structure, architecture and biosynthesis in Escherichia coli. Biochim Biophys Acta 1778: 1714-1734. 
15. Vollmer W, Joris B, Charlier P, Foster S (2008) Bacterial peptidoglycan (murein) hydrolases. FEMS Microbiol Rev 32: 259-286.

16. Holtje JV (1998) Growth of the stress-bearing and shape-maintaining murein sacculus of Escherichia coli. Microbiol Mol Biol Rev 62: 181-203.

17. Amano K, Shibata Y (1992) Structural studies of peptidoglycans in Campylobacter species. Microbiol Immunol 36: 961-967.

18. Weadge JT, Pfeffer JM, Clarke AJ (2005) Identification of a new family of enzymes with potential $\mathrm{O}$-acetylpeptidoglycan esterase activity in both Grampositive and Gram-negative bacteria. BMC Microbiol 5: 49.

19. Sycuro LK, Pincus Z, Gutierrez KD, Biboy J, Stern CA, et al. (2010) Peptidoglycan crosslinking relaxation promotes Helicobacter pylor's helical shape and stomach colonization. Cell 141: 822-833.

20. Bonis M, Ecobichon C, Guadagnini S, Prevost MC, Boneca IG (2010) A M23Bfamily metallopeptidase of Helicobacter pylori required for cell shape, pole formation and virulence. Mol Microbiol 78: 809-819.

21. Hendrixson DR, Akerley BJ, DiRita VJ (2001) Transposon mutagenesis of Campylobacter jejuni identifies a bipartite energy taxis system required for motility. Mol Microbiol 40: 214-224.

22. Sycuro LK, Wyckoff TJ, Biboy J, Born P, Pincus Z, et al. (2012) Multiple peptidoglycan modification networks modulate Helicobacter pylori's cell shape, motility, and colonization potential. PLoS Pathog 8: In press.

23. Karlyshev AV, Wren BW (2005) Development and application of an insertional system for gene delivery and expression in Campylobacter jejuni. Appl Environ Microbiol 71: 4004 4013.

24. Glauner B, Holtje JV, Schwarz U (1988) The composition of the murein of Escherichia coli. J Biol Chem 263: 10088-10095.

25. Bui NK, Gray J, Schwarz H, Schumann P, Blanot D, et al. (2009) The peptidoglycan sacculus of Myxococcus xanthus has unusual structural features and is degraded during glycerol-induced myxospore development. J Bacteriol 191: 494-505.

26. Clarke AJ, Dupont C (1992) O-acetylated peptidoglycan: its occurrence, pathobiological significance, and biosynthesis. Can J Microbiol 38: 85-91.

27. Vollmer W (2008) Structural variation in the glycan strands of bacterial peptidoglycan. FEMS Microbiol Rev 32: 287-306.

28. Szymanski CM, King M, Haardt M, Armstrong GD (1995) Campylobacter jejuni motility and invasion of Caco-2 cells. Infect Immun 63: 4295-4300.

29. van Putten JP, van Alphen LB, Wosten MM, de Zoete MR (2009) Molecular mechanisms of Campylobacter infection. Curr Top Microbiol Immunol 337: 197-229.

30. den Blaauwen T, de Pedro MA, Nguyen-Disteche M, Ayala JA (2008) Morphogenesis of rod-shaped sacculi. FEMS Microbiol Rev 32: 321-344.

31. Gerdes K (2009) RodZ, a new player in bacterial cell morphogenesis. Embo J 28: $171-172$.

32. Uehara T, Park JT (2003) Identification of MpaA, an amidase in Escherichia coli that hydrolyzes the gamma-D-glutamyl-meso-diaminopimelate bond in murein peptides. J Bacteriol 185: 679-682.

33. Arminjon F, Guinand M, Vacheron MJ, Michel G (1977) Specificity profiles of the membrane-bound gamma-D-glutamyl-(L)meso-diaminopimelateendopeptidase and LD-carboxypeptidase from Bacillus sphaericus 9602. Eur J Biochem 73: 557-565.

34. Garnier M, Vacheron MJ, Guinand M, Michel G (1985) Purification and partial characterization of the extracellular gamma-D-glutamyl-(L)meso-diaminopimelate endopeptidase I, from Bacillus sphaericus NCTC 9602. Eur J Biochem 148: 539-543.

35. Hourdou ML, Guinand M, Vacheron MJ, Michel G, Denoroy L, et al. (1993) Characterization of the sporulation-related gamma-D-glutamyl-(L)meso-diaminopimelic-acid-hydrolysing peptidase I of Bacillus sphaericus NCTC 9602 as a member of the metallo(zinc) carboxypeptidase A family. Modular design of the protein. Biochem J 292: 563-570.

36. Costa K, Bacher G, Allmaier G, Dominguez-Bello MG, Engstrand L, et al. (1999) The morphological transition of Helicobacter pylori cells from spiral to coccoid is preceded by a substantial modification of the cell wall. J Bacteriol 181: $3710-3715$.

37. Joshua GW, Guthrie-Irons G, Karlyshev AV, Wren BW (2006) Biofilm formation in Campylobacter jejuni. Microbiology 152: 387-396.

38. Kalmokoff M, Lanthier P, Tremblay TL, Foss M, Lau PC, et al. (2006) Proteomic analysis of Campylobacter jejuni 11168 biofilms reveals a role for the motility complex in biofilm formation. J Bacteriol 188: 4312-4320.

39. Moe KK, Mimura J, Ohnishi T, Wake T, Yamazaki W, et al. (2010) The mode of biofilm formation on smooth surfaces by Campylobacter jejuni. J Vet Med Sci 72: $411-416$.

40. Al-Sayegh AF, Loughlin MF, Dillon E, Mellits KH, Connerton IF (2010) Campylobacter jejuni activates NF-kappaB independently of TLR2, TLR4, Nod1 and Nod2 receptors. Microb Pathog 49: 294-304.

41. Zilbauer M, Dorrell N, Elmi A, Lindley KJ, Schuller S, et al. (2007) A major role for intestinal epithelial nucleotide oligomerization domain 1 (NOD1) in eliciting host bactericidal immune responses to Campylobacter jejuni. Cell Microbiol 9: 2404-2416.

42. Benko S, Philpott DJ, Girardin SE (2008) The microbial and danger signals that activate Nod-like receptors. Cytokine 43: 368-373.

43. Magalhaes JG, Philpott DJ, Nahori MA, Jehanno M, Fritz J, et al. (2005) Murine Nodl but not its human orthologue mediates innate immune detection of tracheal cytotoxin. EMBO Rep 6: 1201-1207.
44. Davis KM, Weiser JN (2011) Modifications to the peptidoglycan backbone help bacteria to establish infection. Infect Immun 79: 562-570.

45. Watson RO, Galan JE (2008) Campylobacter jejuni survives within epithelial cells by avoiding delivery to lysosomes. PLoS Pathog 4: e14.

46. Lee J, Tattoli I, Wojtal KA, Vavricka SR, Philpott DJ, et al. (2009) pHdependent internalization of muramyl peptides from early endosomes enables Nod1 and Nod2 signaling. J Biol Chem 284: 23818-23829.

47. Hasegawa M, Yang K, Hashimoto M, Park JH, Kim YG, et al. (2006) Differential release and distribution of Nodl and Nod2 immunostimulatory molecules among bacterial species and environments. J Biol Chem 281: 29054-29063.

48. Pradipta AR, Fujimoto Y, Hasegawa M, Inohara N, Fukase K (2010) Characterization of natural human nucleotide-binding oligomerization domain protein 1 (Nod1) ligands from bacterial culture supernatant for elucidation of immune modulators in the environment. J Biol Chem 285: 23607-23613.

49. Dalmasso G, Nguyen HT, Charrier-Hisamuddin L, Yan Y, Laroui H, et al. (2010) PepT1 mediates transport of the proinflammatory bacterial tripeptide LAla-\{gamma\}-D-Glu-meso-DAP in intestinal epithelial cells. Am J Physiol Gastrointest Liver Physiol 299: G687-696.

50. Iyer JK, Coggeshall KM (2011) Cutting edge: primary innate immune cells respond efficiently to polymeric peptidoglycan, but not to peptidoglycan monomers. J Immunol 186: 3841-3845.

51. Magalhaes JG, Sorbara MT, Girardin SE, Philpott DJ (2011) What is new with Nods? Curr Opin Immunol 23: 29-34.

52. Kaparakis M, Turnbull L, Carneiro L, Firth S, Coleman HA, et al. (2010) Bacterial membrane vesicles deliver peptidoglycan to NOD1 in epithelial cells. Cell Microbiol 12: 372-385.

53. de Zoete MR, Keestra AM, Roszczenko P, van Putten JP (2010) Activation of human and chicken toll-like receptors by Campylobacter spp. Infect Immun 78: 1229-1238.

54. Friis LM, Keelan M, Taylor DE (2009) Campylobacter jejuni drives MyD88independent interleukin-6 secretion via Toll-like receptor 2. Infect Immun 77: $1553-1560$

55. Kuijf ML, Samsom JN, van Rijs W, Bax M, Huizinga R, et al. (2010) TLR4mediated sensing of Campylobacter jejuni by dendritic cells is determined by sialylation. J Immunol 185: 748-755.

56. Li YP, Vegge CS, Brondsted L, Madsen M, Ingmer H, et al. (2011) Campylobacter jejuni induces an anti-inflammatory response in human intestinal epithelial cells through activation of phosphatidylinositol 3-kinase/Akt pathway. Vet Microbiol 148: 75-83.

57. van Mourik A, Steeghs L, van Laar J, Meiring HD, Hamstra HJ, et al. (2010) Altered linkage of hydroxyacyl chains in lipid A of Campylobacter jejuni reduces TLR4 activation and antimicrobial resistance. J Biol Chem 285: 15828-15836.

58. Watson RO, Galan JE (2005) Signal transduction in Campylobacter jejuni-induced cytokine production. Cell Microbiol 7: 655-665.

59. Hendrixson DR (2006) A phase-variable mechanism controlling the Campylobacter jejuni FlgR response regulator influences commensalism. Mol Microbiol 61: 1646-1659.

60. Hendrixson DR (2008) Restoration of flagellar biosynthesis by varied mutational events in Campylobacter jejuni. Mol Microbiol 70: 519-536.

61. Hendrixson DR, DiRita VJ (2004) Identification of Campylobacter jejuni genes involved in commensal colonization of the chick gastrointestinal tract. Mol Microbiol 52: 471-484.

62. Nachamkin I, Yang XH, Stern NJ (1993) Role of Campylobacter jejuni flagella as colonization factors for three-day-old chicks: analysis with flagellar mutants. Appl Environ Microbiol 59: 1269-1273.

63. Wassenaar TM, van der Zeijst BA, Ayling R, Newell DG (1993) Colonization of chicks by motility mutants of Campylobacter jejuni demonstrates the importance of flagellin A expression. J Gen Microbiol 139: 1171-1175.

64. Wosten MM, Wagenaar JA, van Putten JP (2004) The FlgS/FlgR twocomponent signal transduction system regulates the fla regulon in Campylobacter jejuni. J Biol Chem 279: 16214-16222.

65. Hanel I, Borrmann E, Muller J, Muller W, Pauly B, et al. (2009) Genomic and phenotypic changes of Campylobacter jejuni strains after passage of the chicken gut. Vet Microbiol 136: 121-129.

66. Martinon F, Agostini L, Meylan E, Tschopp J (2004) Identification of bacterial muramyl dipeptide as activator of the NALP3/cryopyrin inflammasome. Curr Biol 14: 1929-1934.

67. Laing KJ, Purcell MK, Winton JR, Hansen JD (2008) A genomic view of the NOD-like receptor family in teleost fish: identification of a novel NLR subfamily in zebrafish. BMC Evol Biol 8: 42.

68. Fernando U, Biswas D, Allan B, Willson P, Potter AA (2007) Influence of Campylobacter jejuni fliA, rpoN and $f l g K$ genes on colonization of the chicken gut. Int J Food Microbiol 118: 194-200.

69. Matz C, van Vliet AH, Ketley JM, Penn CW (2002) Mutational and transcriptional analysis of the Campylobacter jejuni flagellar biosynthesis gene flhB. Microbiology 148: 1679-1685.

70. Wassenaar TM, Bleumink-Pluym NM, van der Zeijst BA (1991) Inactivation of Campylobacter jejuni flagellin genes by homologous recombination demonstrates that flaA but not flaB is required for invasion. Embo J 10: 2055-2061.

71. Hendrixson DR, DiRita VJ (2003) Transcription of sigma54-dependent but not sigma28-dependent flagellar genes in Campylobacter jejuni is associated with formation of the flagellar secretory apparatus. Mol Microbiol 50: 687-702. 
72. Joslin SN, Hendrixson DR (2009) Activation of the Campylobacter jejuni FlgSR two-component system is linked to the flagellar export apparatus. J Bacteriol 191: 2656-2667.

73. Field LH, Underwood JL, Payne SM, Berry LJ (1993) Characteristics of an avirulent Campylobacter jejuni strain and its virulence-enhanced variants. J Med Microbiol 38: 293-300.

74. Gaynor EC, Cawthraw S, Manning G, MacKichan JK, Falkow S, et al. (2004) The genome-sequenced variant of Campylobacter jejuni NCTC 11168 and the original clonal clinical isolate differ markedly in colonization, gene expression, and virulence-associated phenotypes. J Bacteriol 186: 503-517.
75. Ziprin RL, Hume ME, Andrews K, Droleskey RE, Harvey RB, et al. (2005) News and notes: An atypical Campylobacter coli exhibiting unusual morphology. Curr Microbiol 51: 161-163.

76. Svensson SL, Davis LM, MacKichan JK, Allan BJ, Pajaniappan M, et al. (2009) The CprS sensor kinase of the zoonotic pathogen Campylobacter jejuni influences biofilm formation and is required for optimal chick colonization. Mol Microbiol 71: 253-272.

77. Glauner B (1988) Separation and quantification of muropeptides with highperformance liquid chromatography. Anal Biochem 172: 451-464. 